Article

\title{
In Vitro Selection of Probiotics, Prebiotics, and Antioxidants to Develop an Innovative Synbiotic (NatuREN G) and Testing Its Effect in Reducing Uremic Toxins in Fecal Batches from CKD Patients
}

\author{
Mirco Vacca ${ }^{1}\left(\mathbb{D}\right.$, Giuseppe Celano ${ }^{1, * \mathbb{D}}$, Marcello Salvatore Lenucci ${ }^{2} \mathbb{D}$, Sergio Fontana ${ }^{3}$, Flavia Maria la Forgia ${ }^{3}$, \\ Fabio Minervini ${ }^{1} \mathbb{D}$, Aurelia Scarano ${ }^{4} \mathbb{D}$, Angelo Santino ${ }^{4} \mathbb{D}$, Giuseppe Dalfino ${ }^{5}$, Loreto Gesualdo ${ }^{6}$ \\ and Maria De Angelis ${ }^{1}$ (D)
}

Citation: Vacca, M.; Celano, G.; Lenucci, M.S.; Fontana, S.; la Forgia, F.M.; Minervini, F.; Scarano, A.; Santino, A.; Dalfino, G.; Gesualdo, L.; et al. In Vitro Selection of Probiotics, Prebiotics, and Antioxidants to Develop an Innovative Synbiotic (NatuREN G) and Testing Its Effect in Reducing Uremic Toxins in Fecal Batches from CKD Patients. Microorganisms 2021, 9, 1316. https://doi.org/10.3390/ microorganisms 9061316

Academic Editor: Gisèle LaPointe

Received: 13 May 2021

Accepted: 15 June 2021

Published: 17 June 2021

Publisher's Note: MDPI stays neutral with regard to jurisdictional claims in published maps and institutional affiliations.

Copyright: (c) 2021 by the authors. Licensee MDPI, Basel, Switzerland. This article is an open access article distributed under the terms and conditions of the Creative Commons Attribution (CC BY) license (https:/ / creativecommons.org/licenses/by/ $4.0 /)$.
1 Department of Soil Plant and Food Sciences, University of Bari, 70126 Bari, Italy; mirco.vacca@uniba.it (M.V.); fabio.minervini@uniba.it (F.M.); maria.deangelis@uniba.it (M.D.A.)

2 Department of Biological and Environmental Science and Technologies, University of Salento, 73100 Lecce, Italy; marcello.lenucci@unisalento.it

3 Farmalabor srl, 76012 Canosa di Puglia, Italy; s.fontana@farmalabor.it (S.F.); f.laforgia@farmalabor.it (F.M.1.F.)

4 Unit of Lecce, Institute of Sciences of Food Production C.N.R., 73100 Lecce, Italy; aurelia.scarano@ispa.cnr.it (A.S.); angelo.santino@ispa.cnr.it (A.S.)

5 National Institute of Gastroenterology “S. de Bellis" Research Hospital, 70013 Castellana Grotte, Italy; giuseppe.dalfino@irccsdebellis.it

6 Nephrology, Dialysis and Transplantation Unit, Department of Emergency and Organ Transplantation, "Aldo Moro" University, 70124 Bari, Italy; loreto.gesualdo@uniba.it

* Correspondence: giuseppe.celano@uniba.it; Tel.: +39-080-544-2948

Abstract: We aimed to develop an innovative synbiotic formulation for use in reducing dysbiosis, uremic toxins (e.g., $p$-cresol and indoxyl sulfate), and, consequently, the pathognomonic features of patients with chronic kidney disease (CKD). Twenty-five probiotic strains, belonging to lactobacilli and Bifidobacterium, were tested for their ability to grow in co-culture with different vegetable (pomegranate, tomato, and grapes) sources of antioxidants and prebiotics (inulin, fructooligosaccharides, and $\beta$-glucans). Probiotics were selected based on the acidification rates and viable cell counts. Inulin and fructo-oligosaccharides reported the best prebiotic activity, while a pomegranate seed extract was initially chosen as antioxidant source. The investigation was also conducted in fecal batches from healthy and CKD subjects, on which metabolomic analyses (profiling volatile organic compounds and total free amino acids) were conducted. Two out of twenty-five probiotics were finally selected. After the stability tests, the selective innovative synbiotic formulation (named NatuREN G) comprised Bifidobacterium animalis BLC1, Lacticaseibacillus casei LC4P1, fructo-oligosaccharides, inulin, quercetin, resveratrol, and proanthocyanidins. Finally, NatuREN $\mathrm{G}$ was evaluated on fecal batches collected from CKD in which modified the viable cell densities of some cultivable bacterial patterns, increased the concentration of acetic acid and decane, while reduced the concentration of nonanoic acid, dimethyl trisulfide, and indoxyl sulfate.

Keywords: probiotics; prebiotics; antioxidants; microbiota; synbiotic; fecal batches; chronic kidney disease

\section{Introduction}

Chronic kidney disease (CKD) refers to damaged kidneys with decreased capability to filter blood. CKD can evolve into end-stage-renal disease (ESRD), where the kidneys do not work, necessitating dialysis [1,2]. An altered kidney functionality determines an excess of waste metabolites that, accumulating in blood, causes other health problems, such as heart disease and stroke [3]. The incidence of CKD is growing worldwide, becoming a widely recognized problem for public health. The general increase in the average age of the 
population and the decrease in the mortality of patients at risk of renal failure are among the main factors linked to the increased incidence of CKD. Hence, due to the increasing costs for the management of CKD and ESRD patients, researchers are searching for alternative strategies to treat CKD patients.

In the last years, increasing evidence has highlighted that a bidirectional relationship, defined as the renal-gut axis, exists between gut microbes and nephropathy [4,5]. In CKD, renal damage determines an accumulation of urea and nitrogenous compounds in both blood and intestinal lumen [6]. Therefore, urea and its derivatives (i.e., ammonia and other nitrogenous compounds) cause significant deviations in the optimal $\mathrm{pH}$ range of the gut, and both urea and intestinal $\mathrm{pH}$ strongly favor the proliferation of proteolytic bacteria $[7,8]$. From this point of view, the genomic potential of specific bacterial patterns (e.g., Proteobacteria and relative sub-taxa, such as Enterobacteriaceae) determines the production of secondary metabolites, starting from the overabundant nitrogen compounds found in the intestinal lumen of nephropathic subjects [8]. Those secondary metabolites, known as uremic toxins (e.g., trimethylamine- $N$-oxide, TMAO, indoxyl sulfate, IS, and $p$-cresyl sulfate $(p C S))$, cause a worsening of renal function and, therefore, the establishment of a vicious cycle along the renal-gut axis $[9,10]$.

In this context, some novel strategies to treat nephropathy are based on either nutritional therapy (e.g., low- or very-low-protein diets) [11-13] or the use of probiotics and prebiotics, alone or in combination (i.e., synbiotics) [14-17]. The common aim of these alternative strategies is to reduce the typical dysbiosis and symptoms affecting subjects with low kidney functionality, shifting from the dominance of proteolytic gut microbiota to saccharolytic. These strategies also aim to delay ESRD onset and, thus, the need for dialysis. The shift from proteolytic to saccharolytic metabolism firstly leads to a reduction in the production and accumulation of uremic toxins. Additionally, the production of short-chain fatty acids (SCFAs) by saccharolytic bacteria has also been largely recognized as beneficial $[18,19]$ in CKD patients $[17,20,21]$.

Nowadays, a large body of evidence is available about the effects caused by the administration of probiotics and synbiotics to CKD patients [22-26]. The framework of symptomatology linked to CKD is widely recognized, and bacterial patterns and relative metabolites that mark the nephropathy are known. However, one of the major limitations of innovative formulations is the minimal evidence for their efficacy under specific conditions before being applied in vivo. In some cases, probiotics may not be able to survive in specific conditions and/or environments. Consequently, in our opinion, it is necessary to start from in vitro evaluations that simulate the conditions encountered by probiotics and synbiotics used for treating CKD.

Therefore, before proceeding with in vivo evaluation, and to develop an innovative synbiotic with a prospective application in CKD patients, we aimed to select the best combination between probiotics, prebiotics, and antioxidants from vegetables and vegetable extracts. Once found, this combination was used in an innovative formulation aiming to assess, through testing of fecal samples collected from nephropathic patients, its potential effect on affecting the gut microbiota and the concentration of uremic toxins.

\section{Materials and Methods}

\subsection{Microorganisms and Culture Conditions}

Twenty-four probiotic strains, belonging to Bifidobacterium breve (one strain), Bifidobacterium animalis subsp. lactis (two strains), Lactobacillus (L.) acidophilus (two), Lacticaseibacillus (Lc.) casei (three), L. delbrueckii subsp. bulgaricus (one), Lc. paracasei (one), Lactiplantibacillus (Lp.) plantarum (nine), Limosilactobacillus (Ls.) reuteri (two), and Lc. rhamnosus (three), were obtained from either commercially available formulations or animal and human feces. In the latter case, the strains belonged to the Culture Collection of the University of Bari. In addition to pure cultures of probiotic strains, the commercial formulation Synbio 100 (Sacco s.r.1., Cadorago, Italy), which includes Lc. rhamnosus and Lc. paracasei subsp. paracasei in a 1:1 ratio was used in this study. Strains were propagated in MRS broth (Oxoid Ltd., 
Basingstoke, Hampshire, England, UK) for $24 \mathrm{~h}$ at $37^{\circ} \mathrm{C}$, except for Lp. plantarum 12A, Lc. casei LC4P1 and BGP93, and Lc. paracasei 14A, which were cultured at $30^{\circ} \mathrm{C}$.

\subsection{Chemical Characterization of Food Matrices}

Whole tomato fruits or grape skin were frozen in liquid nitrogen, freeze-dried, and finely ground, before extraction with $80 \%$ methanol at $4{ }^{\circ} \mathrm{C}$ overnight. Extracts were centrifuged at $5000 \times \mathrm{g}$ for $20 \mathrm{~min}$ at $4^{\circ} \mathrm{C}$ and supernatants were collected and filtered through a $0.22 \mu \mathrm{m}$ filter. Main polyphenols classes were characterized through HPLC, as reported by Scarano et al. [27]. All analyses were performed in triplicate (sampling replicas) for each extract.

Additionally, four different varieties of pomegranate (Punica granatum L.; Kamel, Emek, Ako, and Wonderful one) were characterized. Briefly, after pomegranate fruit collection, the relative juice was extracted and analyzed for moisture, ash, total soluble solids, and $\mathrm{pH}$. In addition, total carbohydrates, polysaccharides, pectins, starch, sugars, organic acids, ascorbic acid (AsA), and dehydroascorbic acid (DHA) were determined. Lastly, the pomegranate juices were characterized for their antioxidant activity through the determination of soluble and insoluble-bound phenols, flavonoids, proanthocyanidins, and anthocyanins. The detailed methods are reported in Appendix A.

\subsection{Evaluation of Effects Exerted by Antioxidants and Prebiotics on Probiotics Growth}

In order to evaluate the effects of antioxidants on probiotics growth, all tomato extracts and pomegranate juices were tested. In a subsequent step of the workflow, a commercial pomegranate seed extract (Pom.S.E.) (Farmalabor s.r.l., Canosa di Puglia, Italy), with known high levels of antioxidants and low amount of carbohydrates, was also tested.

All the extracts were added at a concentration of $5 \mathrm{~g} / \mathrm{L}$ to laboratory-made MRS (artisanal MRS (artMRS)), which contained peptone $(10 \mathrm{~g} / \mathrm{L})$, meat extract $(10 \mathrm{~g} / \mathrm{L})$, yeast extract $(5 \mathrm{~g} / \mathrm{L})$, glucose $(2 \mathrm{~g} / \mathrm{L})$, di-potassium phosphate $(2 \mathrm{~g} / \mathrm{L})$, sodium acetate $(5 \mathrm{~g} / \mathrm{L})$, tri-ammonium citrate $(2 \mathrm{~g} / \mathrm{L})$, magnesium sulfate $(0.2 \mathrm{~g} / \mathrm{L})$, manganese sulfate $(0.05 \mathrm{~g} / \mathrm{L})$, and Tween 80 (polysorbate, $1 \mathrm{~mL} / \mathrm{L}$ ). After sterilization at $121^{\circ} \mathrm{C}$ for $15 \mathrm{~min}$, probiotics were added at a cell density of $7 \log \mathrm{CFU} / \mathrm{mL}$ and incubated at $37^{\circ} \mathrm{C}$ for $24 \mathrm{~h}$. The $\mathrm{pH}$ variation $(\Delta \mathrm{pH})$ and bacterial cell counts on MRS agar medium (Oxoid Ltd., Basingstoke, Hampshire, England, UK) were determined.

The same workflow was adopted for prebiotics, i.e., inulin, fructo-oligosaccharides (FOS), and $\beta$-glucans. Due to the possible negative or positive effects of food antioxidants on the growth of different intestinal microorganisms, including probiotics, microbiological tests were conducted to select prebiotics even in the presence of antioxidants. Prebiotics were added, singularly or in combination, at a concentration of $5 \mathrm{~g} / \mathrm{L}$ in art-MRS at a 1:1 ratio (each $2.5 \mathrm{~g} / \mathrm{L}$ ) when combined. After sterilization at $121^{\circ} \mathrm{C}$ for $15 \mathrm{~min}$, probiotics were added at a cell density of $7 \log \mathrm{CFU} / \mathrm{mL}$ and incubated at $37^{\circ} \mathrm{C}$ for $24 \mathrm{~h} . \Delta \mathrm{pH}$ and bacterial cell counts were determined, as above.

\subsection{Fecal Media from Healthy Subjects and Chronic Kidney Disease Patients}

To evaluate the capability of selected probiotics to grow in co-culture under conditions simulating the intestinal ecosystem, fecal extracts were used as model media [28]. The fecal media consisted of pooled fecal extracts from five healthy subjects (HC) or five nephropathic patients (CKD; stage IIIb-IV). Briefly, fecal extracts were obtained from human feces (HC or CKD) freshly collected in a sterile stool container. Then, containers were opened under a sterile hood, diluted 1:10 with distilled water, and homogenized with a stomacher (Bag Mixer, Interscience International, Roubaix, France) for $3 \mathrm{~min}$. The obtained suspension was then centrifuged at $14,000 \mathrm{rpm}$ for $15 \mathrm{~min}$. To the supernatant, we added di-potassium phosphate $(2 \mathrm{~g} / \mathrm{L})$, sodium acetate $(5 \mathrm{~g} / \mathrm{L})$, tri-ammonium citrate $(2 \mathrm{~g} / \mathrm{L})$, magnesium sulfate $(0.2 \mathrm{~g} / \mathrm{L})$, manganese sulfate $(0.05 \mathrm{~g} / \mathrm{L})$, Tween 80 (polysorbate, $1 \mathrm{~mL} / \mathrm{L})$, and glucose $(2 \mathrm{~g} / \mathrm{L}$, instead of $20 \mathrm{~g} / \mathrm{L}$ usually used for probiotics growth), and it 
was sterilized at $121^{\circ} \mathrm{C}$ for $15 \mathrm{~min}$. The obtained fecal media were singly inoculated with the selected probiotics at a cell density of $7 \log \mathrm{CFU} / \mathrm{mL}$ and incubated at $37^{\circ} \mathrm{C}$ for $24 \mathrm{~h}$.

\subsection{Amino Acids Extraction and Detection}

Total free amino acids (FAAs) in water-soluble extracts of fecal media were determined using a Biochrom 30 series Amino Acid Analyzer (Biochrom Ltd., Cambridge Science Park, Waterbeach Cambridge, UK), equipped with a sodium cation-exchange column (20 by $0.46 \mathrm{~cm}$, inner diameter), as previously described [29]. The analysis was performed after $24 \mathrm{~h}$ of probiotic growth in fecal media obtained from pooled and sterilized feces of healthy subjects (HC) or chronic kidney disease patients (CKD).

\subsection{Short Chain Fatty Acids Detection}

Short chain fatty acids were detected in fecal media using gas chromatography-mass spectrometry (GC-MS) according to Dixon et al. [30]. Determination was performed using the same samples indicated in Section 2.5. After preconditioning (according to the manufacturer's instructions) a polydimethylsiloxane/divinylbenzene (PDMS/DVB) fiber (65 $\mu \mathrm{m})$, a manual solid-phase micro-extraction (SPME) holder (Supelco Inc., Bellefonte, PA, USA) was used. Before headspace sampling, the fiber was exposed to the gas chromatography (GC) inlet for $1 \mathrm{~h}$ for thermal desorption at $250^{\circ} \mathrm{C}$. Three grams of sample were placed into $10 \mathrm{~mL}$ glass vials, and $10 \mu \mathrm{L}$ of 4-methyl-2-pentanol (final concentration $33 \mathrm{mg} / \mathrm{L}$ ) was added as the internal standard. Samples were then equilibrated for $10 \mathrm{~min}$ at $40{ }^{\circ} \mathrm{C}$. The SPME fiber was exposed to each sample for $40 \mathrm{~min}$. Equilibration and absorption phases were conducted under stirring. The fiber was then inserted into the injection port of the gas chromatograph for $10 \mathrm{~min}$ of sample desorption. GC-mass spectrometry (MS) analyses were performed with an Agilent 7890A gas chromatograph (Agilent Technologies, Palo Alto, CA, USA) coupled to an Agilent 5975C mass selective detector, operating in electron impact mode (ionization voltage, $70 \mathrm{eV}$ ). A Supelcowax 10 capillary column (length, $60 \mathrm{~m}$; inner diameter, $0.32 \mathrm{~mm}$; Supelco, Bellefonte, PA, USA) was used. The temperature program was $50{ }^{\circ} \mathrm{C}$ for $1 \mathrm{~min}$, followed by an increase at a rate of $4.5^{\circ} \mathrm{C} / \mathrm{min}$ to $65^{\circ} \mathrm{C}$, an increase at a rate of $10{ }^{\circ} \mathrm{C} / \mathrm{min}$ to $230^{\circ} \mathrm{C}$, and then holding at $230^{\circ} \mathrm{C}$ for $25 \mathrm{~min}$ [31]. The injector, interface, and ion source temperatures were kept at 250,250 , and $230{ }^{\circ} \mathrm{C}$, respectively. The mass-to-charge ratio interval was 30 to $350 \mathrm{Da}$ and spectra were acquired at a rate of 2.9 scans per second. Injection was carried out in splitless mode, and helium (flow rate $=1 \mathrm{~mL} / \mathrm{min}$ ) was used as the carrier gas. Molecules were identified based on the comparison of their retention times with those of pure compounds (Sigma-Aldrich, Milan, Italy). Identities were confirmed by searching mass spectra in the available databases (NIST, version 2005; Wiley, version 1996). Quantitative data for the identified compounds were obtained by interpolation of the relative area versus the internal standard area. All the GC-MS raw files were converted into netCDF format via Chemstation (Agilent Technologies, Santa Clara, CA, USA) and subsequently processed through the XCMS toolbox (http://metlin.scripps.edu/download/; accessed date: 1 December 2020). XCMS software allows for automatic and simultaneous retention time alignment, matched filtration, peak detection, and peak matching. GC-MS/SPME data were organized in matrices for subsequent statistical analysis.

\subsection{In Vitro Effects of the Innovative Synbiotic Formulation on the Fecal Microbiota of HC and CKD Subjects}

The above-described HC and CKD fecal media were inoculated with $1 \%(w / w)$ of fresh feces from a healthy volunteer or a CKD patient, separately, to constitute the fecal batches. Feces obtained from the two volunteers were collected in sterile stool containers filled over $4 / 5$, with the aim of reducing the headspace. Then, fresh fecal samples were processed within $6 \mathrm{~h}$ from the collection, according to the guidelines used for fecal microbiota transplantation [32]. To both fecal batches (HC and CKD), we also added the developed innovative synbiotic formulation and incubated the batches at $37^{\circ} \mathrm{C}$ for $24 \mathrm{~h}$ under anaerobic conditions. The cultivable bacteria were enumerated before and after incubation. Three 
independent determinations were carried out for each pool, as previously described [29]. Ten grams of fecal batches was homogenized with $40 \mathrm{~mL}$ of sterilized physiological solution $(0.9 \%$ of sodium chloride $(v / v))$. Diluted fecal batches were inoculated in plates containing the following selective media: plate count agar (total facultative aerobes and anaerobes); MRS agar (lactic acid bacteria); Bifidobacterium agar modified (Bifidobacteria) (Becton Dickinson France SA, Le Pont de Claix, France); Mannitol salt agar (staphylococci); Wilkins-Chalgren anaerobe agar (total anaerobes); Wilkins-Chalgren anaerobe agar plus GN selective supplements and defibrinated sheep blood (Bacteroides, Porphyromonas, and Prevotella); MacConkey agar No2 (Enterobacteriaceae); Rogosa agar plus $1.32 \mathrm{~mL} / \mathrm{L}$ of glacial acetic acid (lactobacilli); GSP agar (Fluka) plus penicillin-G (100,000 IU/L) (Pseudomonas, Aeromonas); Slanetz and Bartley (enterococci). Excluding both Bifidobacterium modified agar and GSP agar, all media were purchased from Oxoid.

\subsection{Uremic Toxins Detection}

Concentrations of uremic toxins were determined on two samples obtained from each of the two fecal batches (HC and CKD), to which we added the developed innovative synbiotic. The baseline values $(\mathrm{t} 0)$ were determined immediately after the addition of fresh feces to fecal media. The uremic toxins amount was also evaluated after incubation at $37^{\circ} \mathrm{C}$ (t24). Concentrations of uremic toxins were determined through nuclear magnetic resonance (NMR) analysis, according to Beaumont et al. [33]. Briefly, $70 \mathrm{mg}$ of each sample was homogenized with $1.3 \mathrm{~mL}$ NMR buffer for $5 \mathrm{~min}$; the homogenate was centrifuged $\left(13,000 \times \mathrm{g}\right.$ for $10 \mathrm{~min}$ at $\left.4{ }^{\circ} \mathrm{C}\right)$, and the supernatant transferred into $5 \mathrm{~mm}$ tubes for NMR spectroscopy. After processing, spectra were digitalized and imported in MATLAB (version 2014b) to calculate the uremic toxins concentration.

\subsection{Statistical Analyses}

Data were subjected to one-way ANOVA; a paired comparison of treatment means was carried out by Tukey's procedure, with $p<0.05$ indicating statistically significant differences, using the statistical software Statistica for Windows (Statistica Software 7.0, Palo Alto, CA, USA).

\section{Results}

\subsection{Characterization of Food Matrices Rich in Antioxidants}

The four varieties of tomato (wild type (WT), Indigo, ResTom, and Bronze) used in the present work were previously characterized for their polyphenol content (flavonoids, stilbenoids, and anthocyanins) and their anti-inflammatory effects in colitis mouse models [27]. Among the varieties, ResTom is rich in stilbenoids, Indigo in flavonoids and anthocyanins, and Bronze contains a remarkable amount of all three polyphenols. Compared with the WT, the presence of high levels of polyphenols in all the transgenic varieties (Indigo, ResTom, and Bronze) agree with the antioxidant activity of the hydrophilic fractions extracted from ripe fruits, with Bronze showing the highest activity (Supplementary Table S1).

The results of chemical characterization of pomegranate juices (Kamel, Emek, Ako, and Wonderful one) are shown in Supplementary Table S2.

\subsection{Acidification and Growth of Probiotics in Presence of Antioxidants and Food Matrices}

To identify the antioxidant(s) to include in our innovative synbiotic formulation, freeze-dried tomato and pomegranate juice extracts were tested. Compared with the control (artMRS), only B. animalis BLC1 and Ls. reuteri ATCC23272 showed a higher $\triangle \mathrm{pH}$ when grown in artMRS + Bronze or artMRS + Indigo, respectively (Figure 1C). The highest $\Delta \mathrm{pH}$ values were found in artMRS + WT tomato extracts (Figure 1A), where 8 out of 25 tested probiotics showed the best acidification rate (Figure 1C). Among the four pomegranate varieties, the highest acidification $(\Delta \mathrm{pH})$ was found for probiotics cultured in media with juice from either Ako or Emek (Figure 1B,C). 

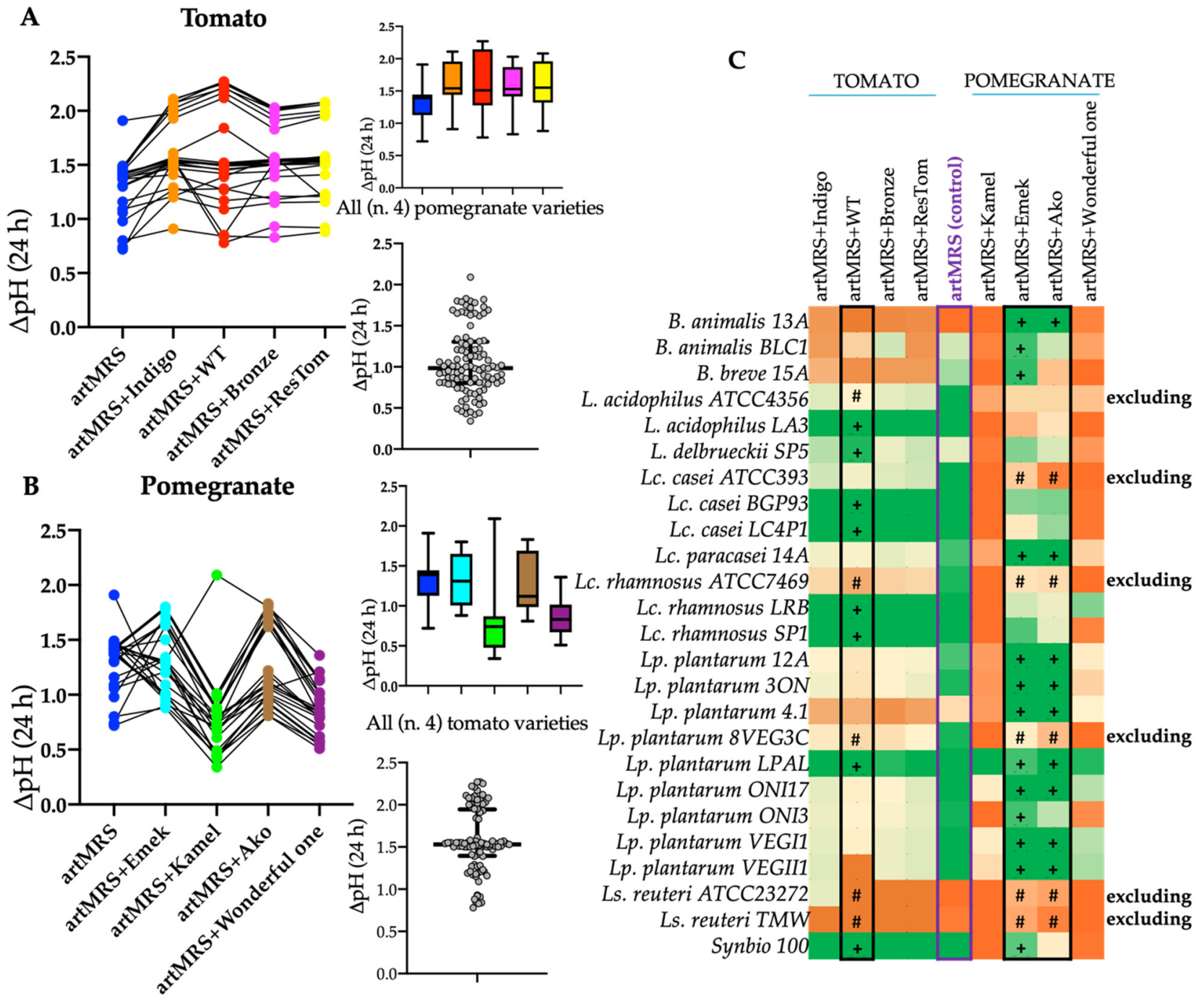

Figure 1. Acidification rate $(\Delta \mathrm{pH})$ after $24 \mathrm{~h}$ of probiotic growth at $37^{\circ} \mathrm{C}$ in artisanal MRS with $2 \mathrm{~g} / \mathrm{L}$ of glucose (artMRS) used alone, as a control, or supplemented with different antioxidant matrices ( $5 \mathrm{~g} / \mathrm{L})$. (A) Evaluation of lyophilized tomato extract from four different varieties, specifically Indigo (artMRS + Indigo), wild type (artMRS + WT), Bronze (artMRS + Bronze), and ResTom (artMRS + ResTom). (B) Evaluation of pomegranate juices of four different varieties, specifically Kamel (artMRS + Kamel), Emek (artMRS + Emek), Ako (artMRS + Ako), and Wonderful one (artMRS + Wonderful one). (C) Heatmap of the $\Delta \mathrm{pH}$ values found in media supplemented with lyophilized tomato extracts and pomegranate juices after $24 \mathrm{~h}$ of probiotics growth; values range from dark orange (lower $\Delta \mathrm{pH}$ values, $<25$ th percentile) to dark green (higher $\Delta \mathrm{pH}$ values, $>75$ th percentile), with light yellow corresponding to intermediate $\Delta \mathrm{pH}$ values (50th percentile). Data are presented as the average of at least one biological triplicate \pm standard deviation (SD). Inside the heatmap, \# indicates that the tested condition determined the exclusion of the probiotics, whereas + indicates that the tested condition determined the selection of the probiotics.

Due to the low acidification observed when cultured in the presence of antioxidants, $L$. acidophilus ATCC4356, Lc. casei ATCC393, Lc. rhamnosus ATCC7469, Ls. reuteri ATCC23272 and TMW, and Lp. plantarum 8VEG3C were excluded from further analyses. In agreement with acidification, the remaining 19 probiotics were able to grow in the presence of antioxidants (data not shown).

The same workflow was also adopted for prebiotics, specifically $\beta$-glucans, inulin, and fructo-oligosaccharides (FOS). Compared with the control (artMRS), strains grown on artMRS with inulin or FOS showed similar or higher $\Delta \mathrm{pH}$ values (Figure 2A). 
A

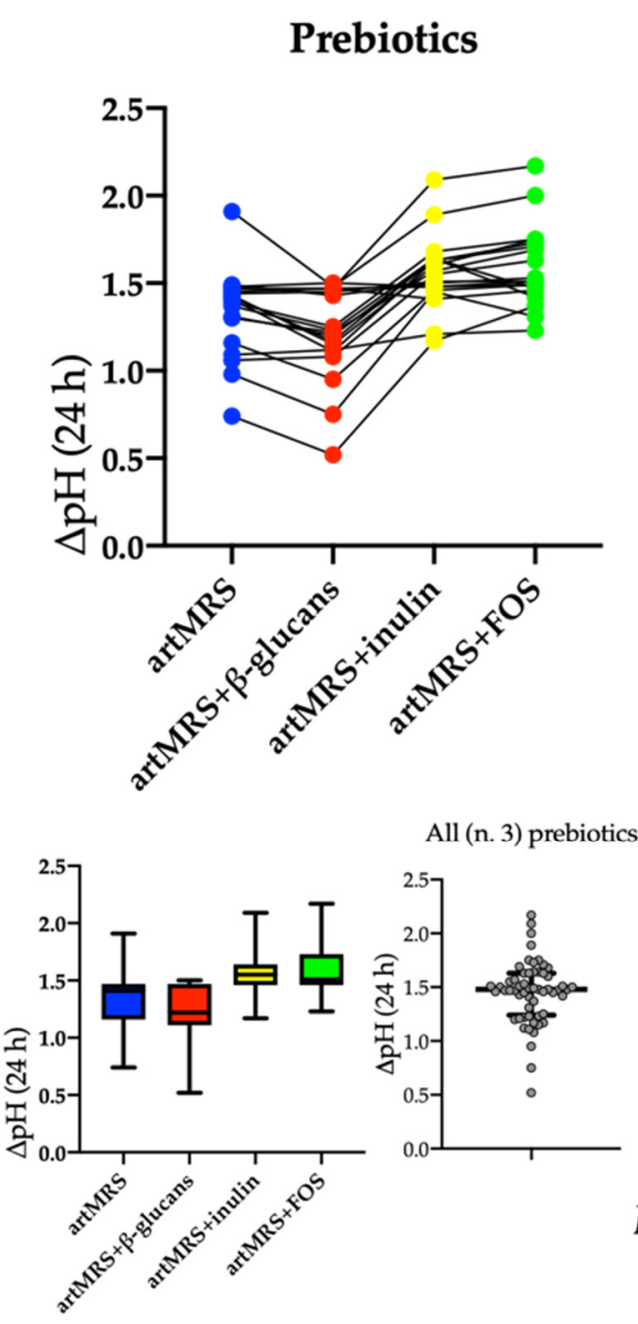

B

\author{
B. animalis $13 A$ \\ B. animalis BLC1 \\ B. breve $15 A$ \\ L. acidophilus $L A 3$ \\ L. delbrueckii SP5 \\ Lc. casei BGP93 \\ Lc. casei LC4P1
}

Lc. paracasei $14 A$

Lc. rhamnosus $L R B$

Lc. rhamnosus SP1

Lp. plantarum $12 A$

Lp. plantarum $30 N$

Lp. plantarum 4.1

Lp. plantarum LPAL

Lp. plantarum ONI17

Lp. plantarum ONI3

Lp. plantarum VEGI1

Lp. plantarum VEGII1

Synbio 100
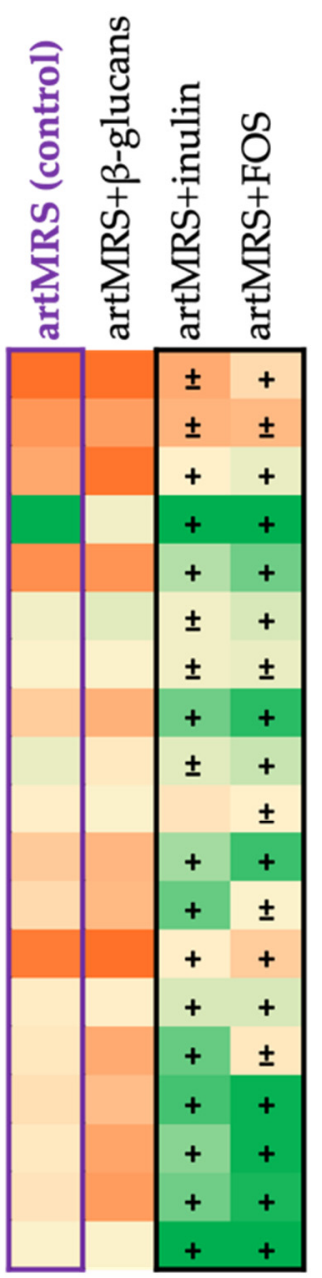

Figure 2. (A) Acidification rate $(\Delta \mathrm{pH})$ after $24 \mathrm{~h}$ of probiotic growth at $37{ }^{\circ} \mathrm{C}$ in artisanal MRS with $2 \mathrm{~g} / \mathrm{L}$ of glucose (artMRS) used alone as a control or supplemented with prebiotics $(5 \mathrm{~g} / \mathrm{L})$, specifically $\beta$-glucans (artMRS $+\beta$-glucans), inulin (artMRS + inulin), and FOS (artMRS + FOS). (B) Heatmap of the $\Delta \mathrm{pH}$ values found in artMRS supplemented with different prebiotics after $24 \mathrm{~h}$ of probiotics growth; values range from dark orange (lower $\Delta \mathrm{pH}$ values, $<25$ th percentile) to dark green (higher $\Delta \mathrm{pH}$ values, $>75$ th percentile), whereas light yellow corresponds to intermediate $\Delta \mathrm{pH}$ values (50th percentile). Data are presented as the average of one biological triplicate $\pm \mathrm{SD}$. Inside the heatmap, indicates a $\Delta \mathrm{pH}$ higher than the control, whereas \pm indicates a $\Delta \mathrm{pH}$ similar to the control.

In agreement with the acidification results, all the 19 tested probiotics were able to grow on artMRS with inulin or FOS. Probiotics cultured in the presence of inulin showed, on average, a higher cell density than when cultured in the presence of FOS (Figure 3). 


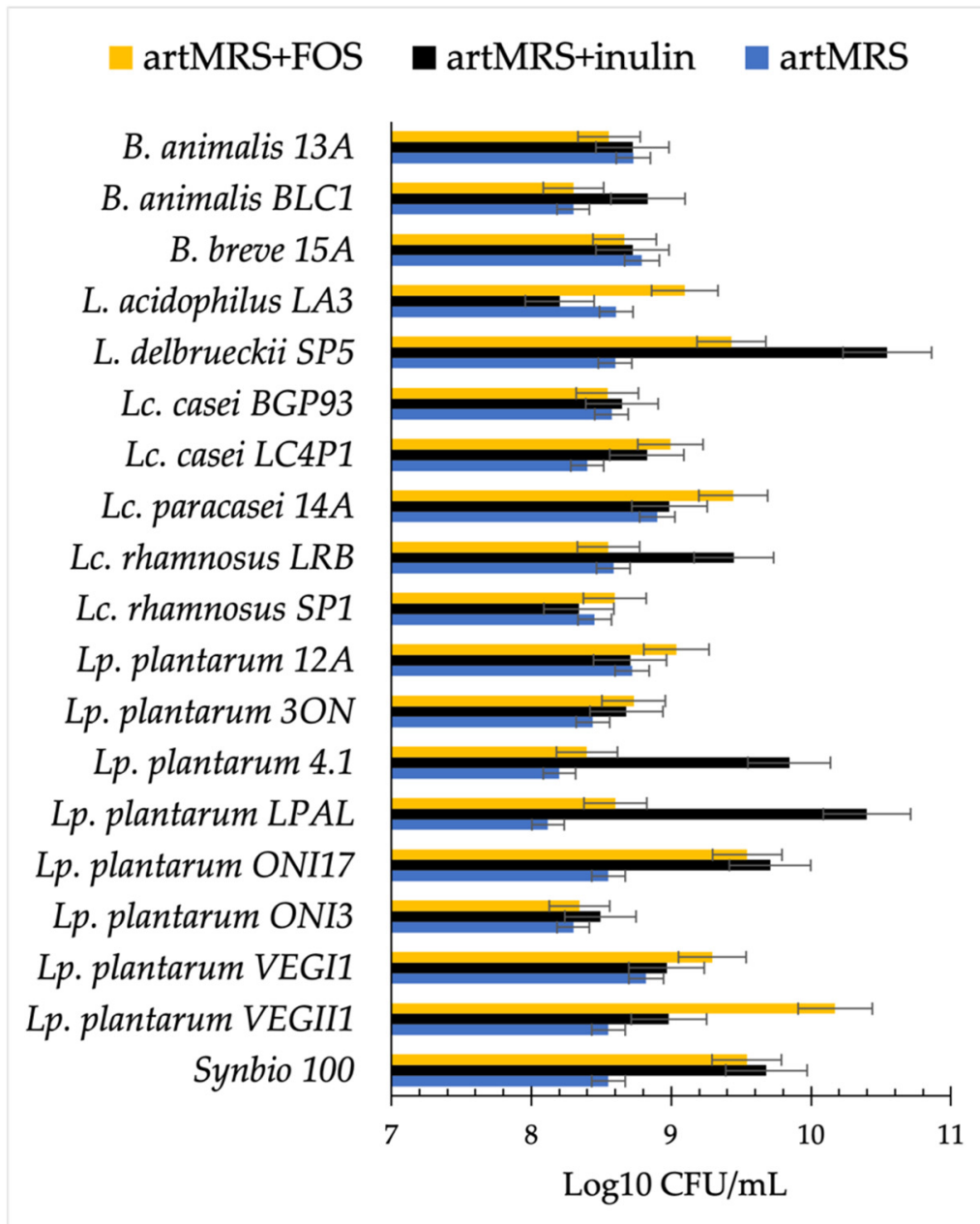

Figure 3. Viable cell count (log CFU/mL) of probiotics after $24 \mathrm{~h}$ of growth at $37^{\circ} \mathrm{C}$ in artisanal MRS ( $2 \mathrm{~g} / \mathrm{L}$ of glucose (artMRS)) with the addition of fructo-oligosaccharides (artMRS + FOS, $5 \mathrm{~g} / \mathrm{L}$ ) or inulin (artMRS + inulin, $5 \mathrm{~g} / \mathrm{L}$ ). Data are presented as the average of one biological triplicate $\pm \mathrm{SD}$.

Due to the high carbohydrate concentrations in Ako and Emek pomegranate juice extracts, a further analysis was conducted using a commercial pomegranate seed extract (Pom.S.E.) characterized by a small amount (traces) of carbohydrates. The degree of acidification was evaluated, comparing the control (artMRS) with the following conditions: (i) $\operatorname{artMRS~+~Pom.S.E.~(5~g/L),~(ii)~artMRS~+~Pom.S.E.~(5~g/L)~+~FOS~(5~g/L),~and~(iii)~}$ artMRS+ Pom.S.E. $(5 \mathrm{~g} / \mathrm{L})+$ FOS $(2.5 \mathrm{~g} / \mathrm{L})+$ inulin $(2.5 \mathrm{~g} / \mathrm{L})$. The selected probiotics showed the lowest $\mathrm{pH}$ values when grown on medium with added FOS + inulin (Table 1). Compared with the control, 12 of the 19 probiotics showed a difference in $\mathrm{pH}$ value that was higher than or equal to $0.3 \mathrm{pH}$ units.

The viable cell counts of the most acidifying strains $(n=12)$ were determined. After $24 \mathrm{~h}$ of incubation, cell density increased (1-3 logarithmic cycles) in all the theses (Figure 4). More specifically, B. animalis 13A; Lc. paracasei 14A; and Lp. plantarum strains LPAL, 12A, and ONI3 showed the highest cell density in the presence of Pom.S.E. and both the prebiotics (FOS and inulin). L. delbrueckii SP5; Lp. plantarum ONI3, LPAL, and VEGI1; and Lc. paracasei 14A showed an increase in the presence of Pom.S.E. and FOS. Based on these results, as well as on the higher acidification observed in the presence of both prebiotics, the condition containing FOS, inulin, and Pom.S.E. was chosen for further analyses. 
Table 1. Acidification of probiotics in artisanal MRS (artMRS) used alone (as a control) or supplemented with pomegranate seed extract (Pom.S.E., 5 g/L), or Pom.S.E. + fructo-oligosaccharides (FOS) (each 5 g/L), or Pom.S.E. (5 g/L) + FOS (2.5 g/L) + inulin $(2.5 \mathrm{~g} / \mathrm{L})$. The difference in acidification degree (Diff.Ac.Deg.) between the control and the thesis reporting the lowest $\mathrm{pH}$ values (Pom.S.E. + FOS+ inulin) is reported in the last column. Data are presented as the average of one biological triplicate $\pm \mathrm{SD}$.

\begin{tabular}{|c|c|c|c|c|c|}
\hline Probiotics & $\begin{array}{c}\mathrm{pH} \\
\operatorname{artMRS}\end{array}$ & $\begin{array}{c}\mathrm{pH} \\
\operatorname{artMRS}+\text { Pom.S.E. }\end{array}$ & $\begin{array}{c}\mathrm{pH} \\
\text { artMRS + Pom.S.E. + } \\
\text { FOS }\end{array}$ & $\begin{array}{c}\mathrm{pH} \\
\text { artMRS + Pom.S.E. + } \\
\text { FOS + inu }\end{array}$ & $\begin{array}{c}\text { (Diff.Ac.Deg.) } \\
\text { pH artMRS - pH } \\
\text { artMRS + Pom.S.E. + } \\
\text { FOS + inu }\end{array}$ \\
\hline B. animalis $13 A$ & $5.66 \pm 0.12^{\mathrm{a}}$ & $5.51 \pm 0.11^{a b}$ & $5.37 \pm 0.11^{b c}$ & $5.26 \pm 0.04^{\mathrm{c}}$ & $\underline{0.40 \pm 0.08}$ \\
\hline B. animalis BLC1 & $5.31 \pm 0.10^{\mathrm{a}}$ & $5.23 \pm 0.06^{\mathrm{a}}$ & $5.02 \pm 0.11^{\mathrm{b}}$ & $4.86 \pm 0.08^{b}$ & $\overline{0.45 \pm 0.09}$ \\
\hline B. breve $15 A$ & $5.24 \pm 0.07^{\mathrm{a}}$ & $5.15 \pm 0.10^{\mathrm{a}}$ & $4.91 \pm 0.12^{b c}$ & $4.77 \pm 0.03^{c}$ & $\overline{0.47 \pm 0.05}$ \\
\hline L. acidophilus LA3 & $4.83 \pm 0.09^{\mathrm{a}}$ & $4.78 \pm 0.10^{\mathrm{ab}}$ & $4.65 \pm 0.04^{b}$ & $4.59 \pm 0.11^{b}$ & $\overline{0.24 \pm 0.10}$ \\
\hline L. delbrueckii SP5 & $5.34 \pm 0.11^{\mathrm{a}}$ & $5.21 \pm 0.03^{a}$ & $5.02 \pm 0.12^{b}$ & $4.86 \pm 0.09^{b}$ & $0.48 \pm 0.10$ \\
\hline Lc. casei BGP93 & $4.92 \pm 0.06^{\mathrm{a}}$ & $4.94 \pm 0.08^{a}$ & $4.81 \pm 0.11^{\mathrm{ab}}$ & $4.74 \pm 0.07^{b}$ & $0.18 \pm 0.07$ \\
\hline Lc. casei LC4P1 & $4.93 \pm 0.08^{a}$ & $4.95 \pm 0.06^{\mathrm{a}}$ & $4.70 \pm 0.11^{b}$ & $4.56 \pm 0.05^{b}$ & $0.37 \pm 0.07$ \\
\hline Lc. paracasei $14 A$ & $5.09 \pm 0.05^{\mathrm{a}}$ & $4.92 \pm 0.05^{b}$ & $4.80 \pm 0.04^{c}$ & $4.69 \pm 0.11^{\mathrm{c}}$ & $\overline{0.40 \pm 0.08}$ \\
\hline Lc. rhamnosus $L R B$ & $4.91 \pm 0.10^{\mathrm{a}}$ & $4.99 \pm 0.08^{a}$ & $4.88 \pm 0.08^{a b}$ & $4.81 \pm 0.04^{b}$ & $0.10 \pm 0.07$ \\
\hline Lc. rhamnosus SP1 & $4.95 \pm 0.10^{\mathrm{a}}$ & $4.98 \pm 0.02^{\mathrm{a}}$ & $4.88 \pm 0.11^{\mathrm{ab}}$ & $4.80 \pm 0.11^{b}$ & $0.15 \pm 0.11$ \\
\hline Lp. plantarum $12 A$ & $5.10 \pm 0.10^{a}$ & $4.92 \pm 0.02^{b}$ & $4.81 \pm 0.03^{c}$ & $4.69 \pm 0.12^{c}$ & $0.41 \pm 0.11$ \\
\hline Lp. plantarum $30 N$ & $5.03 \pm 0.08^{a}$ & $4.95 \pm 0.10^{\mathrm{ab}}$ & $4.84 \pm 0.05^{b c}$ & $4.69 \pm 0.10^{\mathrm{c}}$ & $0.34 \pm 0.09$ \\
\hline Lp. plantarum 4.1 & $5.42 \pm 0.10^{\mathrm{a}}$ & $5.37 \pm 0.10^{\mathrm{ab}}$ & $5.26 \pm 0.06^{b c}$ & $5.19 \pm 0.04^{\mathrm{c}}$ & $\overline{0.23 \pm 0.07}$ \\
\hline Lp. plantarum $L P A L$ & $4.96 \pm 0.07^{\mathrm{a}}$ & $4.91 \pm 0.10^{\mathrm{ab}}$ & $4.78 \pm 0.06^{\mathrm{b}}$ & $4.66 \pm 0.02^{c}$ & $0.30 \pm 0.05$ \\
\hline Lp. plantarum ONI17 & $4.98 \pm 0.11^{\mathrm{a}}$ & $4.97 \pm 0.07^{\mathrm{a}}$ & $4.90 \pm 0.11^{\mathrm{ab}}$ & $4.83 \pm 0.05^{b}$ & $\overline{0.15 \pm 0.08}$ \\
\hline Lp. plantarum ONI3 & $5.01 \pm 0.06^{\mathrm{a}}$ & $4.91 \pm 0.05^{\mathrm{ab}}$ & $4.78 \pm 0.08^{b c}$ & $4.67 \pm 0.03^{c}$ & $\underline{0.34 \pm 0.05}$ \\
\hline Lp. plantarum VEGI1 & $4.97 \pm 0.12^{\mathrm{a}}$ & $4.95 \pm 0.02^{\mathrm{a}}$ & $4.78 \pm 0.10^{\mathrm{ab}}$ & $4.67 \pm 0.11^{b}$ & $\overline{0.30 \pm 0.12}$ \\
\hline Lp. plantarum VEGII1 & $4.99 \pm 0.05^{\mathrm{a}}$ & $5.02 \pm 0.11^{\mathrm{ab}}$ & $4.89 \pm 0.04^{b}$ & $4.83 \pm 0.12^{b}$ & $0.16 \pm 0.09$ \\
\hline Synbio 100 & $4.93 \pm 0.10^{\mathrm{a}}$ & $5.06 \pm 0.10^{a}$ & $4.34 \pm 0.04^{b}$ & $4.10 \pm 0.10^{c}$ & $0.83 \pm 0.10$ \\
\hline
\end{tabular}

${ }^{*}$ artMRS = artisanal MRS ( $\mathrm{g} / \mathrm{L}$ of glucose). ${ }^{\mathrm{a}-\mathrm{c}}$ Values within the same column showing different superscript letter are significantly different (Tukey's test, $p<0.05$ ). Within the last column, underlined values showed the selected probiotics.

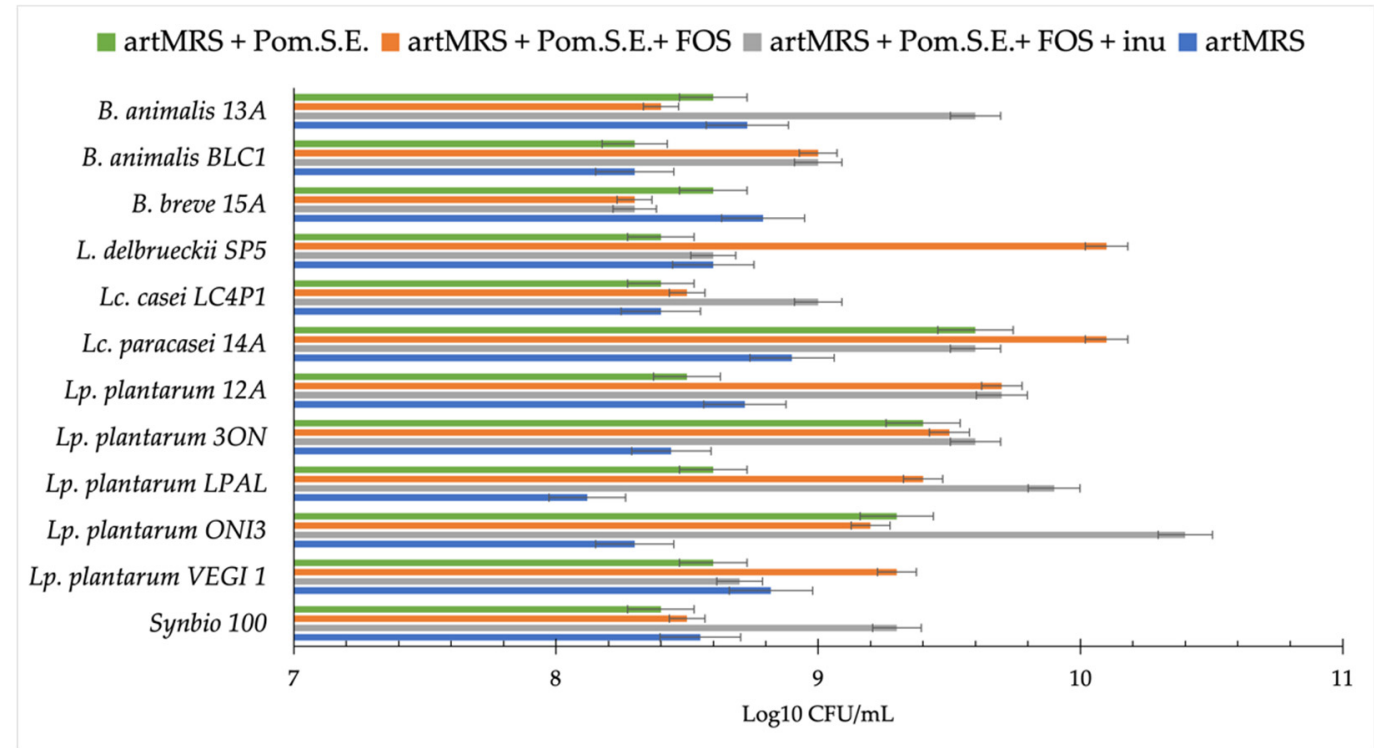

Figure 4. Probiotics viable cell count $(\log \mathrm{CFU} / \mathrm{mL})$ after $24 \mathrm{~h}$ of growth at $37{ }^{\circ} \mathrm{C}$ in artisanal MRS $(2 \mathrm{~g} / \mathrm{L}$ of glucose; artMRS) used alone (as a control) or supplemented with pomegranate seed extract (Pom.S.E.; 5 g/L), or Pom.S.E. + fructooligosaccharides (FOS) (both $5 \mathrm{~g} / \mathrm{L})$, or Pom.S.E. $(5 \mathrm{~g} / \mathrm{L})+$ FOS $(2.5 \mathrm{~g} / \mathrm{L})+$ inulin $(2.5 \mathrm{~g} / \mathrm{L})$. Data are presented as the average of one biological triplicate $\pm \mathrm{SD}$. 


\subsection{Acidification and Growth of Probiotics on Fecal Media from Healthy and Chronic Kidney Disease Subjects}

Twelve probiotics (B. breve 15A; B. animalis BLC1 and 13A; L. delbrueckii SP5; Lc. casei LCP1; Lc. paracasei 14A; Lp. plantarum LPAL, VEGI 1, ONI3, 3ON, and 12A; and Synbio 100), showing the highest acidification and growth on media containing antioxidant food matrices and prebiotics, were tested for their ability to grow in fecal media.

Fresh fecal samples were collected from five healthy subjects (HC), pooled, and used to produce HC fecal medium. To the fecal medium, we added glucose $(2 \mathrm{~g} / \mathrm{L})$, dietary fibers (FOS + inulin, each $2.5 \mathrm{~g} / \mathrm{L}$ ), and/or antioxidants ( $5 \mathrm{~g} / \mathrm{L}$ ). More specifically, the following six experimental treatments were tested:

- The-1: HC fecal media + FOS + inulin.

- The-2: HC fecal media + FOS inulin + Pom.S.E.

- The-3a: HC fecal media + FOS + inulin + tomato extract variety ResTom.

- The-3b: HC fecal media + FOS + inulin + tom. ex. var. Indigo.

- The-3c: HC fecal media + FOS + inulin + tom. ex. var. Bronze.

- The-3d: HC fecal media + FOS + inulin + tom. ex. from WT tomato.

In addition, $\mathrm{HC}$ fecal medium with only glucose added was used as the control. Each fecal medium was inoculated with the selected probiotics. After $24 \mathrm{~h}$ of incubation, most of the probiotics acidified the fecal media, showing a $\Delta \mathrm{pH}$ ranging from 0.2 to 0.4 (Figure 5A). B. animalis BLC1 showed the highest $\Delta \mathrm{pH}$ (value: 0.78 ) when inoculated in The-1, whereas B. breve 15A showed the highest $\Delta \mathrm{pH}$ (value: 0.60 ) in The-2. Probably due to the production of basic compounds (e.g., $\mathrm{NH}_{3}$ ), some strains showed a $\mathrm{pH}$ increase, specifically $L c$. casei LC4P1 grown The- 1 and The-3d ( -0.18 and -0.19 , respectively) and L $p$. plantarum ONI3 grown in The-2 (-0.15).

A

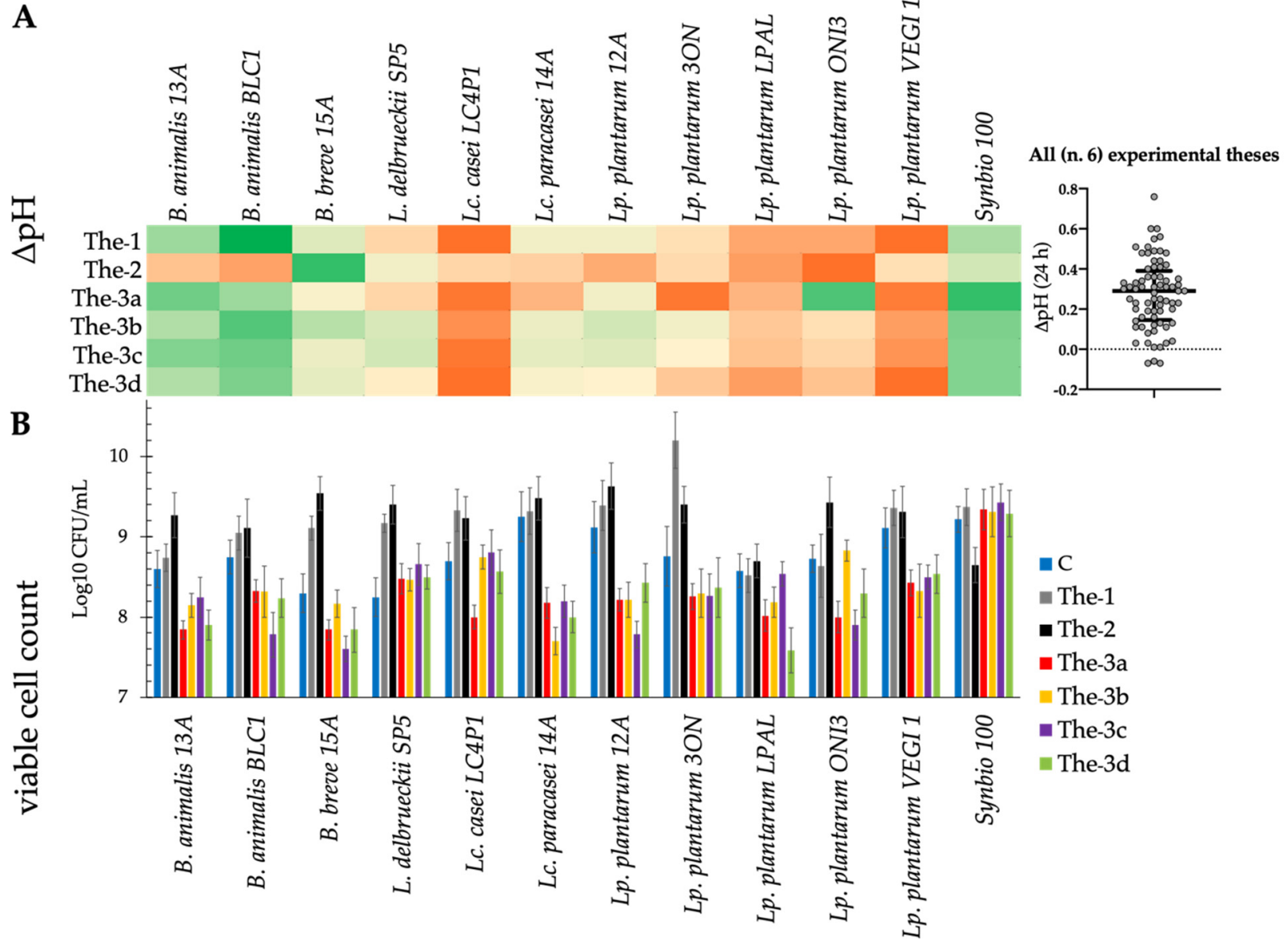

Figure 5. (A) Heatmap of the fecal media acidification degree $(\Delta \mathrm{pH})$ after $24 \mathrm{~h}$ of probiotic growth at $37^{\circ} \mathrm{C}$; values range 
from dark orange (lower $\Delta \mathrm{pH}$ values, $<25$ th percentile) to dark green (higher $\Delta \mathrm{pH}$ values, $>75$ th percentile), while light yellow values correspond to intermediate $\Delta \mathrm{pH}$ values (50th percentile). All fecal media were obtained using pooled fecal extracts of healthy subjects (HC) adding a low content of glucose $(2 \mathrm{~g} / \mathrm{L})$. Prebiotic supplements (FOS and inulin) were added at a concentration of $2.5 \mathrm{~g} / \mathrm{L}$, while antioxidant ones (Pom.S.E. and tomato extracts) were added at a concentration of 5 g/L. Experimental treatments: The-1, HC fecal media + FOS + inulin; The-2, HC fecal media + FOS + inulin + Pom.S.E.; The-3a, HC fecal media + FOS + inulin + tomato extract var. ResTom; The-3b, HC fecal media + FOS + inulin + tomato extract var. Indigo; The-3c, HC fecal media + FOS + inulin + tomato extract var. Bronze; The-3d, HC fecal media + FOS + inulin + tomato extract from WT tomato. (B) Probiotics viable cell count (log CFU/mL) after 24 h of growth at $37^{\circ} \mathrm{C}$ in fecal media obtained from pooled fecal extracts of healthy subjects (HC) with the addition of a low content of glucose (2 g/L). Control (C): fecal medium with pooled HC fecal extracts + glucose $(2 \mathrm{~g} / \mathrm{L})$. The experimental treatments (The- 1 , The- 2 , The-3a, The-3b, The-3c, and The-3d) are reported above. Data are presented as the average of one biological triplicate \pm SD.

All the probiotics showed an increase (about 1-2 logarithmic cycles) in cell density (Figure 5B). Compared with the control, almost all probiotics showed higher cell count when cultured in the presence of prebiotics alone (The-1) or in combination with pomegranate extract (The-2). The only exception was Synbio 100 in The-2. In presence of tomato extracts (The- $3 a$, The- $3 b$, The-3c, and The-3d), all the strains showed cell density values similar to or lower than that of the control.

Therefore, probiotics growth was assessed in fecal media prepared starting from pooled feces from patients with chronic kidney disease (CKD). The experimental treatments, in which probiotics were singly added, were:

- $\quad \mathrm{FM}(\mathrm{CKD})+\mathrm{FOS}+\mathrm{inu}($ The- 1$)=\mathrm{CKD}$ fecal extract + glucose $(2 \mathrm{~g} / \mathrm{L})+\mathrm{FOS}(2.5 \mathrm{~g} / \mathrm{L})+$ inulin $(2.5 \mathrm{~g} / \mathrm{L})$;

- $\quad \mathrm{FM}(\mathrm{CKD})+\mathrm{FOS}+\mathrm{inu}+$ Pom.S.E. $($ The- 2$)=\mathrm{CKD}$ fecal extract + glucose $(2 \mathrm{~g} / \mathrm{L})+\mathrm{FOS}$ $(2.5 \mathrm{~g} / \mathrm{L})+\operatorname{inulin}(2.5 \mathrm{~g} / \mathrm{L})+$ pomegranate seed extract $(5 \mathrm{~g} / \mathrm{L})$.

In addition, a CKD fecal medium, with the addition of glucose only, was used as the control, called FM(CKD).

Except for B. animalis 13A grown in the presence of both prebiotics and pomegranate, all the probiotics showed an increase of at least one logarithmic cycle. Compared with the control, lower viable cell counts were found for B. animalis 13A and Synbio 100 when grown in the presence of prebiotics and pomegranate seed extract. In contrast, under the same conditions, lactobacilli showed a viable cell count that was equal to or higher than that of the control (Figure 6). Therefore, considering the goal of including antioxidants in our innovative synbiotic, the treatment with FOS, inulin, and Pom.S.E. was used to proceed with further analyses.

\subsection{Concentrations of Total Free Amino Acids}

To develop a synbiotic that is potentially usable in CKD patients, the concentrations of the total free amino acids (total FAAs) of the 12 probiotics were analyzed. Fecal extracts from the fresh feces of HC and CKD subjects were used to constitute two different types of fecal media. These fecal media were supplemented with FOS, inulin, and Pom.S.E. (2.5:2.5:5 g/L, respectively) and singly inoculated with probiotics. After incubation, the concentration of total FAAs was lower than $800 \mathrm{mg} / \mathrm{L}$ in the HC fecal media. Conversely, in fecal media obtained from CKD, only 4 (B. animalis BLC1, L. delbrueckii SP5, Lc. casei LC4P1, and Lp. plantarum LPAL) of the 12 probiotic strains showed a concentration of FAAs lower than $800 \mathrm{mg} / \mathrm{L}$ (Figure 7). These four strains showed a significantly lower concentration of total FAAs in CKD fecal media compared with the fecal media obtained using $\mathrm{HC}$ feces and were, therefore, selected. 


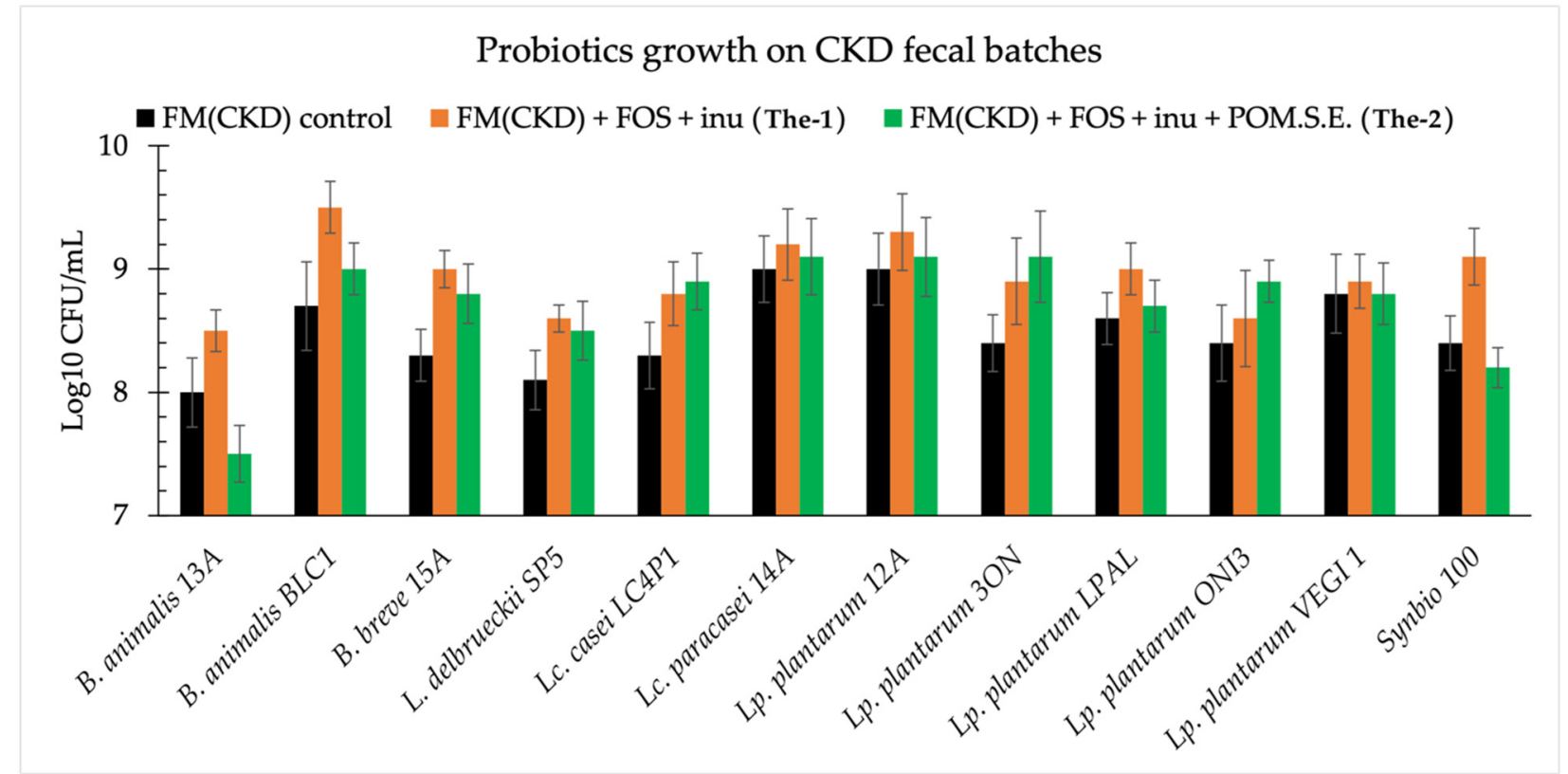

Figure 6. Probiotics growth in fecal media (FM) obtained using feces from chronic kidney disease (CKD) patients with the addition of $2 \mathrm{~g} / \mathrm{L}$ of glucose, which was named FM(CKD), FM (CKD) + FOS (2.5 g/L) + inulin (2.5 g/L), and FM(CKD) + FOS $(2.5 \mathrm{~g} / \mathrm{L})+$ inulin $(2.5 \mathrm{~g} / \mathrm{L})+$ pomegranate seed extract (Pom.S.E.; $5 \mathrm{~g} / \mathrm{L})$. Data are presented as the average of one biological triplicate \pm SD.

\section{Total FAA}

- $\mathrm{FM}(\mathrm{HC})+\mathrm{FOS}+\mathrm{inu}+$ Pom.S.E. $\quad \mathrm{FM}(\mathrm{CKD})+\mathrm{FOS}+\mathrm{inu}+$ Pom.S.E.

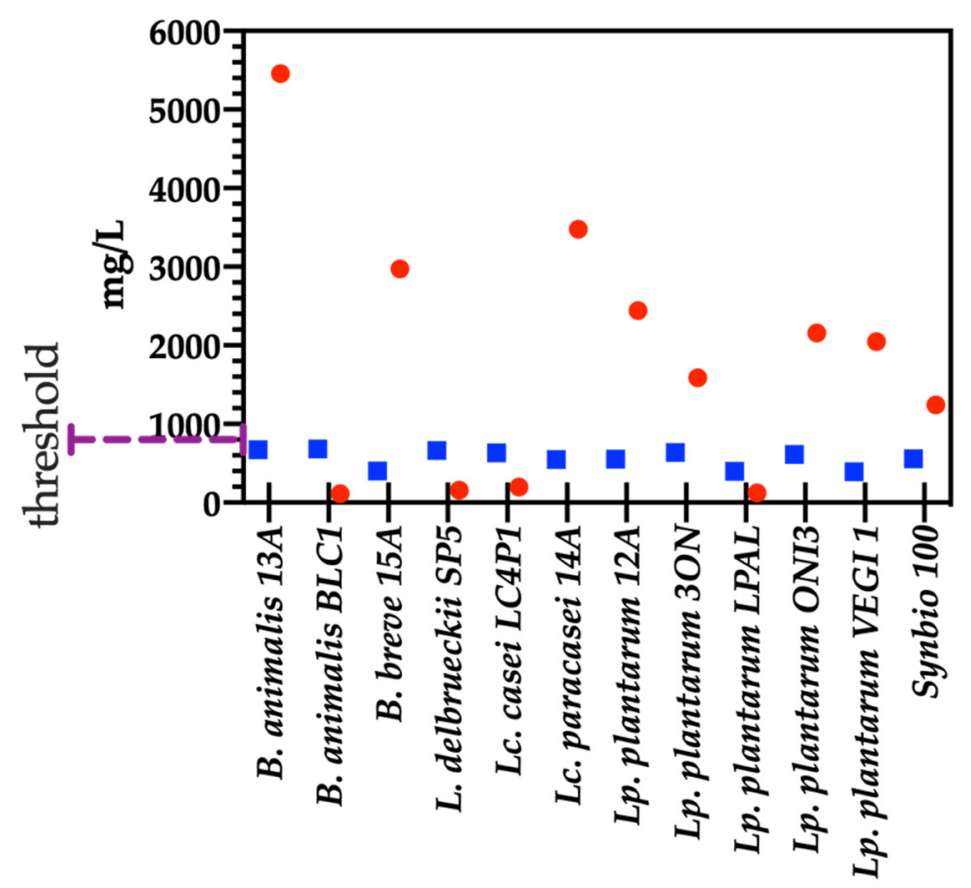

Figure 7. Concentrations of total free amino acids (FAAs, $\mathrm{mg} / \mathrm{L}$ ) after $24 \mathrm{~h}$ of probiotics growth in fecal media (FM) obtained from pooled feces of healthy subjects (HC) or chronic kidney disease patients $(\mathrm{CKD})+2 \mathrm{~g} / \mathrm{L}$ of glucose + FOS $(2.5 \mathrm{~g} / \mathrm{L})+$ inulin $(\mathrm{inu} ; 2.5 \mathrm{~g} / \mathrm{L})+$ pomegranate seed extract (Pom.S.E.; $5 \mathrm{~g} / \mathrm{L}$ ). Data are reported as the average of one technical triplicate. 


\subsection{Concentration of Short Chain Fatty Acids}

Gas chromatography-mass spectrometry (GC-MS) analysis was conducted to evaluate the ability of the four selected probiotic strains to produce short-chain fatty acids (SCFAs). FOS and inulin (each $2.5 \mathrm{~g} / \mathrm{L}$ ) were added to fecal extracts from $\mathrm{HC}$ to constitute a HC fecal medium. B. animalis BLC1, L. delbrueckii SP5, Lc. casei LC4P1, and Lp. plantarum LPAL were inoculated at a cell density of $7 \log \mathrm{CFU} / \mathrm{mL}$. After $24 \mathrm{~h}$ at $37^{\circ} \mathrm{C}$, Lp. plantarum LPAL and Lc. casei LC4P1 were able to produce the highest amounts (ppm equivalents) of acetic acid (Figure 8). Moreover, Lc. casei LC4P1 produced higher amounts of both butanoic and propanoic acids than $L p$. plantarum LPAL. The highest concentration of hexanoic acid was found in the HC fecal media inoculated with B. animalis BLC1. Therefore, B. animalis BLC1 and $L c$. casei LC4P1 were selected as the best SCFA-producing probiotics.

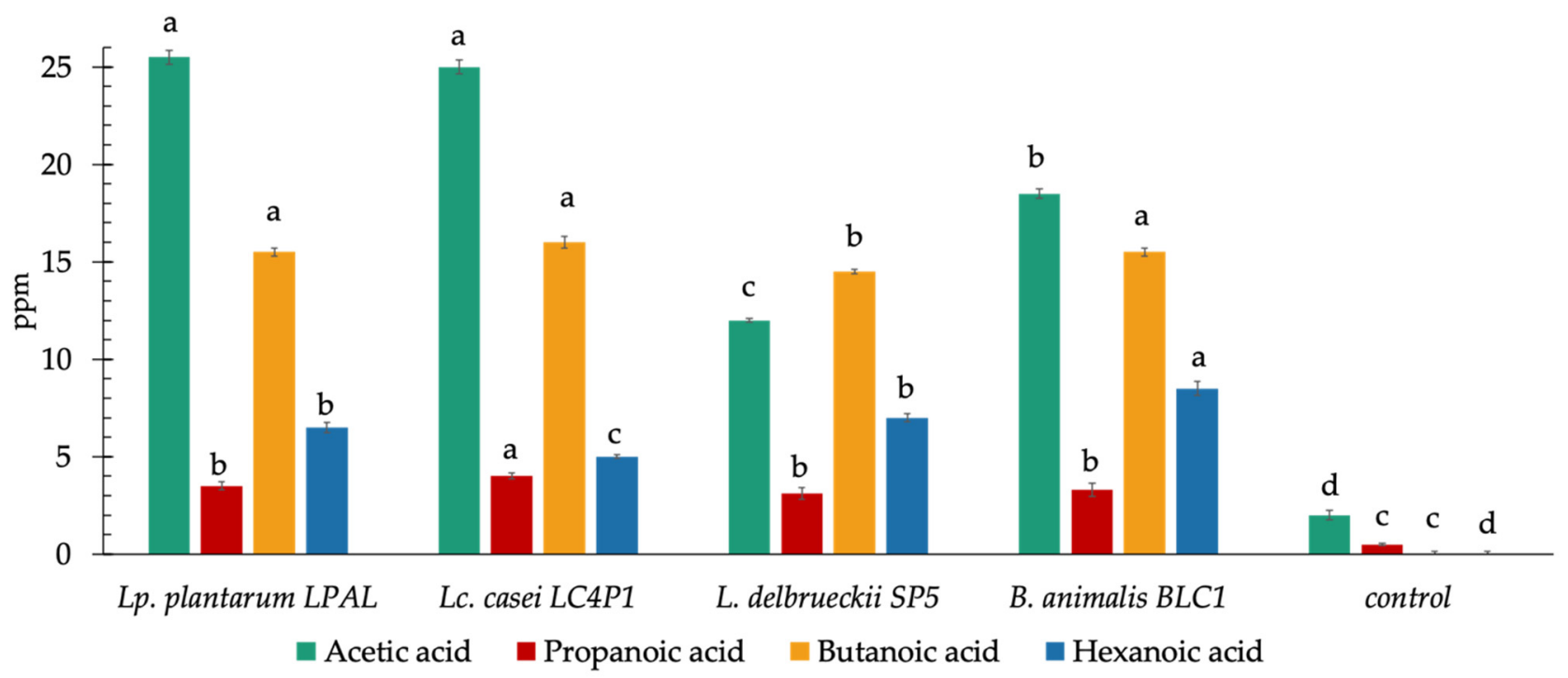

Figure 8. Concentrations of short-chain fatty acids (SCFAs; ppm equivalents) produced by four probiotic strains after $24 \mathrm{~h}$ of growth in fecal media obtained from feces of HC patients with the addition of FOS and inulin (2.5 g/L each). A sterilized fecal medium without the addition of bacterial cells was used as the control. Data are reported as the average of one technical triplicate $\pm \mathrm{SD}$. ${ }^{\text {a-d }}$ Among same metabolite, different superscript letters showed a significant difference $(p<0.05)$.

\subsection{Stability Test of the Innovative Synbiotic Formulation}

A first innovative synbiotic, named NatuREN P, was constituted as follows:

- $\quad$ B. animalis BLC1 (ca. $0.24 \mathrm{~g}=10^{9}$ cells);

- Lc. casei $\mathrm{LC} 4 \mathrm{P} 1$ (ca. $0.24 \mathrm{~g}=10^{9}$ cells);

- $\quad$ FOS (2.5 g);

- Inulin (2.5 g);

- Pomegranate seed extract (0.2 g);

- Maltodextrins from corn $(0.5 \mathrm{~g})$;

- Sodium cyclamate $(0.01 \mathrm{~g})$.

As reported above, the initial cell density of the probiotic strains was about $9 \log$ $\mathrm{CFU} / \mathrm{g}$ of lyophilized cells (minimum daily dose referring to each individual strain). To ascertain the survival of strains in the formulation, their cell density was estimated. The results showed that the cell density of probiotics underwent a decrease of one or more logarithmic cycles after 2 months at both room $\left(20 / 30^{\circ} \mathrm{C}\right)$ and refrigerated $\left(2 / 8^{\circ} \mathrm{C}\right)$ temperature.

As Indigo, ResTom, and Bronze are transgenic varieties and their use is, therefore, limited to studies in mouse models, we searched for a mixture of phenolic compounds approaching the profiles of polyphenols and antioxidants of transgenic tomato varieties. Our previous results $[27,34]$ showed that $10 \%$ red grape skin extract was able to reduce intestinal 
inflammation in a colitis mouse model. Based on the polyphenol profiles of Bronze tomato and red grape skin (Supplementary Table S3), we decided to use a polyphenol mixture (named Polimix), simultaneously approaching the polyphenols content of Bronze tomato and red grape skin extract. More specifically, Polimix includes quercetin, resveratrol, and proanthocyanidins in a ratio of $64: 23: 13$. Polimix was added $(5 \mathrm{~g} / \mathrm{L})$ to artMRS $+2.5 \mathrm{~g} / \mathrm{L}$ of FOS $+2.5 \mathrm{~g} / \mathrm{L}$ of inulin, as already performed, to assess the growth of probiotics in the presence of pomegranate seed extract (Pom.S.E.). A control medium without Polimix was used. Acidification and viable cell count of the two best SCFA-producing probiotics ( $B$. animalis BLC1 and Lc. casei LC4P1) were evaluated after $24 \mathrm{~h}$ at $37^{\circ} \mathrm{C}$. The other 17 probiotics reported in Table 1 were only used for comparison. Among bifidobacterial strains, $B$. animalis BLC1 showed the highest $\triangle \mathrm{pH}$ and a slightly higher cell count than $B$. breve 15A (Supplementary Figure S1A). Among the lactobacilli, L. delbrueckii SP5 showed the highest $\Delta \mathrm{pH}$ (Supplementary Figure S1A), whereas Lc. casei LC4P1 had the highest cell count (Supplementary Figure S1B).

Hence, considering the SCFA produced by the 19 probiotics and, in line with the selection criterion previously adopted, a second innovative synbiotic formulation was constituted as follows, and was named NatuREN G:

- B. animalis BLC1 (ca. $0.24 \mathrm{~g}=10^{9}$ cells);

- Lc. casei LC4P1 (ca. $0.24 \mathrm{~g}=10^{9}$ cells);

- $\quad$ FOS (2.5 g);

- Inulin (2.5 g);

- Quercetin (0.064 g);

- $\quad$ Resveratrol (0.023 g);

- Grapeseed (Vitis vinifera L.) powder extract $(0.013 \mathrm{~g})$, proanthocyanidins (tit. $95 \%$ d.extr.);

- Maltodextrins from corn $(0.5 \mathrm{~g})$;

- Sodium cyclamate $(0.01 \mathrm{~g})$.

In contrast to NatuREN P, in NatuREN G, the probiotics' cell density remained approximately stable after two months of storage at both room $\left(20 / 30^{\circ} \mathrm{C}\right)$ and refrigerated $\left(2 / 8^{\circ} \mathrm{C}\right)$ temperatures. After 6 months of storage, a slight decrease in cell density was found, but the values of cell density were higher than $8 \log C F U / g$. The main findings leading to the constitution of NatuREN G are summarized in Table S4.

\subsection{Effects of NatuREN G on Fecal Microbiota of HC and CKD Subjects}

To evaluate the in vitro effect(s) of NatuREN G on CKD, viable bacterial cell counts were determined after adding fresh feces from HC and CKD subjects to fecal media, with the aim of mimicking the composition of gut microbial community. Cultivable bacteria in $\mathrm{HC}$ and CKD subjects were estimated at baseline (T0) and after $24 \mathrm{~h}$ of incubation at $37^{\circ} \mathrm{C}$, with or without NatuREN G, under anaerobic conditions.

The results of cell densities of the main gut cultivable bacterial groups were elaborated using principal components analysis (PCA). At T0, CKD samples were mainly characterized by high Enterobacteriaceae and staphylococci and low lactic acid bacteria (LABs) and lactobacilli (Figure 9). The opposite was found in HC samples at T0. The addition of NatuREN G determined after $24 \mathrm{~h}$ showed a shift in CKD samples (CKD-NG-t24) toward the side of the PCA factor-plan wherein all the HC samples had fallen. This was mainly determined by the increase in the viable cell count of both LABs and lactobacilli. Differently, $24 \mathrm{~h}$ after adding NatuREN G to HC samples (HC-NG-t24), an increase in viable cell count of the groups Bacteroides-Prevotella-Porphyromonas, Pseudomonas-Aeromonas, and particularly of the bifidobacterial taxa, was found. This increase was related to decreases in total bacterial, total anaerobes, and Enterococcus. Few differences in the HC and CKD samples where NatuREN G had not been added were found compared with T0. 

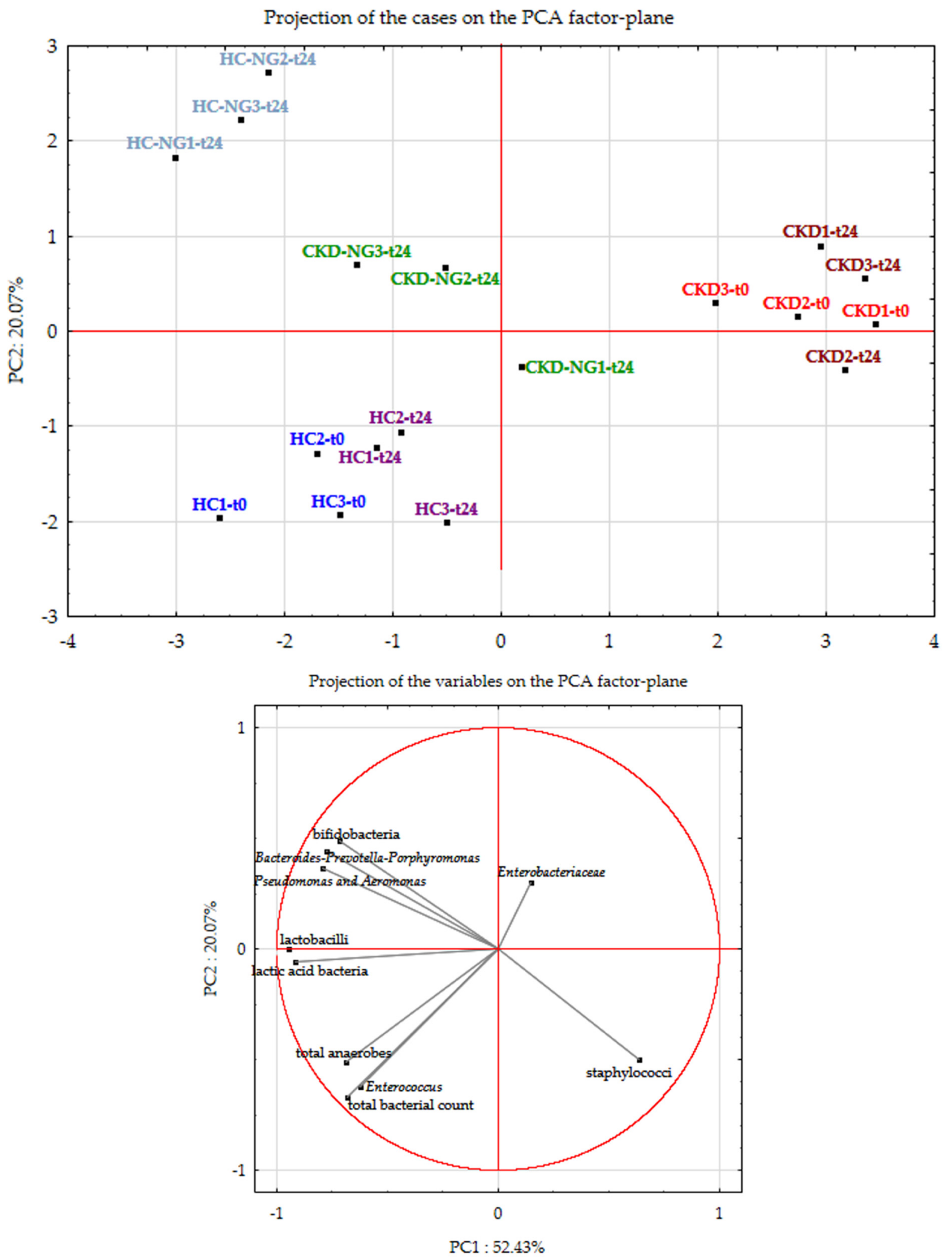

Figure 9. Principal components analysis (PCA) of the main cultivable bacteria found in fecal batches fabricated using sterilized fecal media with the addition of feces from healthy (HC) or nephropathic (CKD) subjects. Data obtained from three independent analyses were collected from baseline samples (sterilized fecal media with fresh feces added, named t0), after $24 \mathrm{~h}$ of incubation at $37^{\circ} \mathrm{C}$ (t24), and $24 \mathrm{~h}$ at $37^{\circ} \mathrm{C}$ after adding the innovative synbiotic NatuREN G (NG-t24). 
The analysis of volatile organic compounds (VOCs) showed that NatuREN G produced significant variations in VOCs, particularly in fecal batches obtained from CKD patients (CKD + NGt24). Few differences (e.g., decreases in nonanoic acid and 1-pentanol) were found in batches obtained from HC fecal extracts (Figure 10). Decane increased in $\mathrm{HC}(\mathrm{HC}+\mathrm{NGt} 24)$ and CKD (CKD + NGt24) fecal batches after $24 \mathrm{~h}$ of the addition of the innovative synbiotic. Similar to $\mathrm{HC}+\mathrm{NG}$, the nonanoic acid decreased in CKD at t24. Different from HC + NGt24, acetic acid was significantly increased in CKD + NGt24 batches. Interestingly, CKD + NGt24 contained a higher concentration of propanoic acid than HC + NGt24. Additionally, in CKD samples where NatuREN G was not added, an increase in dimethyl trisulfide was found. Conversely, dimethyl trisulfide was significantly decreased after $24 \mathrm{~h}$ of incubation of the CKD fecal batch with the addition of NatuREN G.

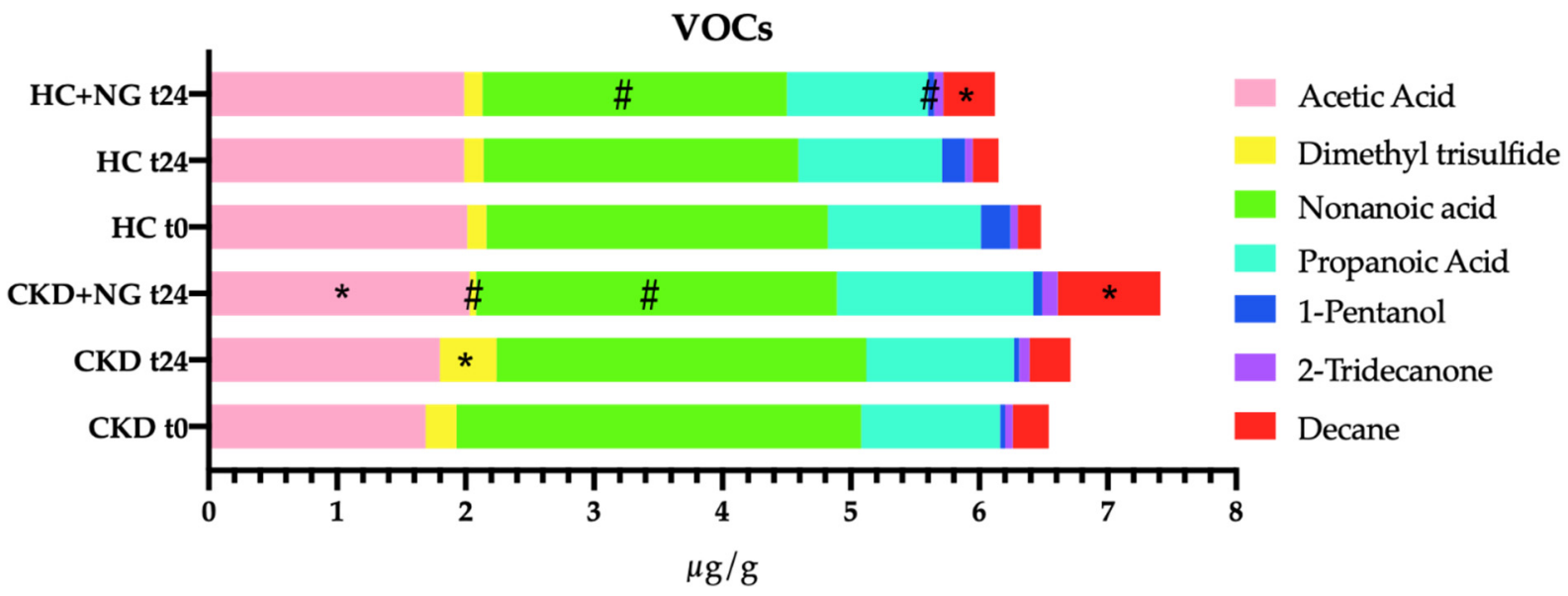

Figure 10. Concentrations of some volatile organic compounds (VOCs; $\mu \mathrm{g} / \mathrm{g}$ ) found in fecal batches obtained by adding fresh feces from a healthy (HC) or nephropathic (CKD) subject to fecal media obtained with pooled and sterilized HC and CKD fecal extracts. The analysis was conducted immediately on fecal batches $(\mathrm{t} 0)$ after $24 \mathrm{~h}$ without adding the innovative synbiotic NatuREN G (t24), and $24 \mathrm{~h}$ after adding the innovative synbiotic NatuREN G (+NGt24). Data are presented as the average of one biological triplicate $\pm \mathrm{SD}$. * significantly increased VOC compared with the relative t0; \#, significantly decreased VOC compared with the relative t0 (Tukey's test, $p<0.05$ ).

An analysis of uremic toxins by nuclear magnetic resonance (NMR) was carried out with fresh fecal samples obtained from CKD and HC subjects to evaluate the effects of NatuREN G after $24 \mathrm{~h}$ of incubation. Parallel fecal samples, without the addition of NatuREN $\mathrm{G}$, were used as controls. The uremic toxin detection was also evaluated immediately after the addition of fresh feces to fecal media ( $\mathrm{t} 0$ ). No significant differences were found in $\mathrm{HC}$ samples, comparing concentrations of uremic toxins in both the incubated $\mathrm{HC}$ samples (with and without NatuREN G, HCt24 and HC + NGt24, respectively) with the baseline values (HCt0) (Figure 11A). Conversely, indole, $p$-cresol, and $p$-cresyl sulfate significantly increased after $24 \mathrm{~h}$ of incubation in CKD samples without the addition of NatuREN G (CKDt24). Furthermore, a significant decrease in indoxyl sulfate was detected comparing CKD + NGt24 to the relative baseline samples (CKDt0) (Figure 11A). The analysis of free amino acids (FAAs) of the above-described fresh fecal samples showed that phenylalanine, tryptophan, and tyrosine significantly decreased in CKD samples with NatuREN G (CKD + NGt24) compared with both CKDt0 and CKDt24 (Figure 11B). On the contrary, no differences were found comparing all the HC samples. 
A

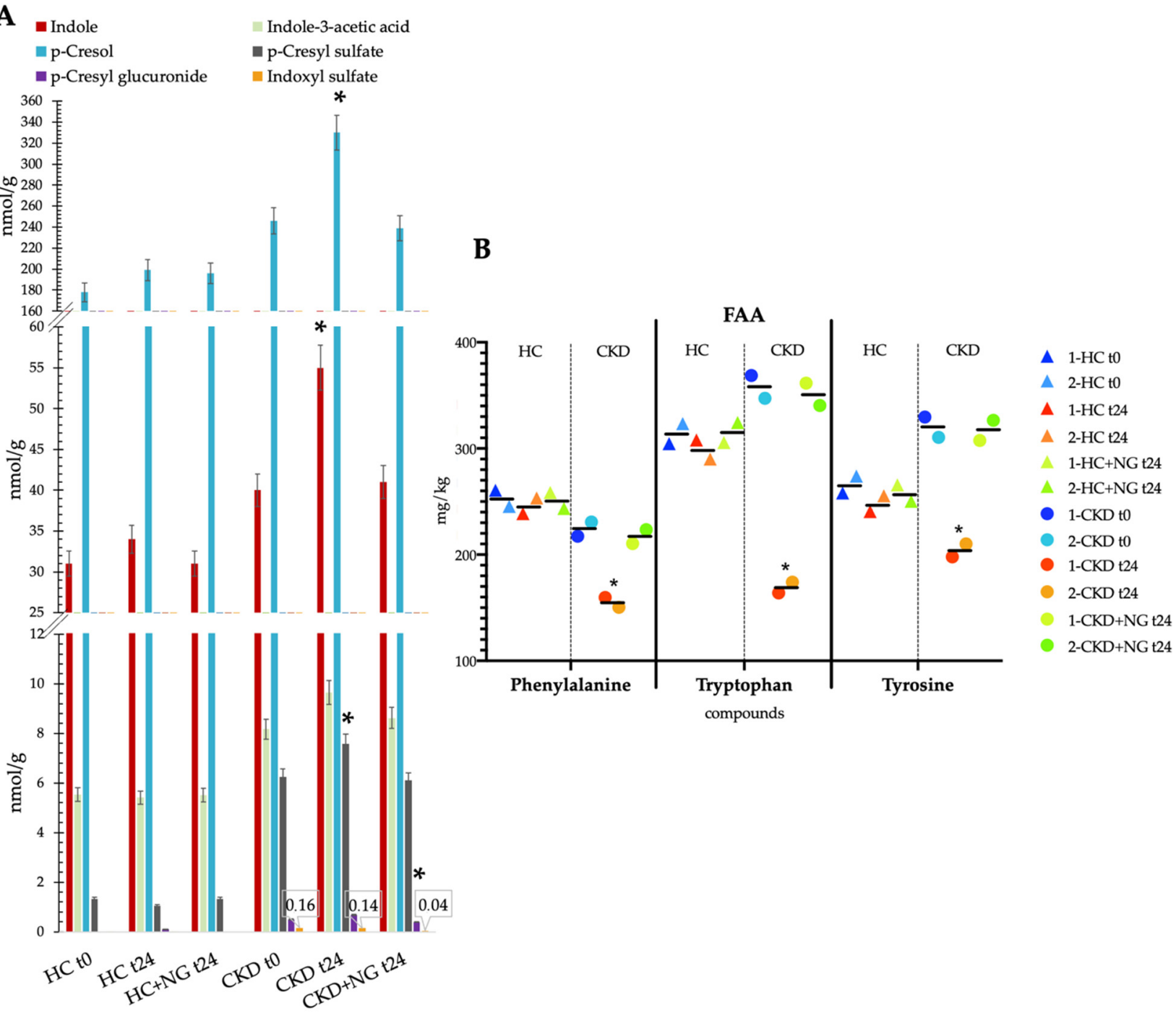

Figure 11. Fecal metabolites (nmol/g wet fecal batch) detection of (A) uremic toxins by nuclear magnetic resonance (NMR) and (B) uremic toxins precursors by amino acid analysis in chronic kidney disease (CKD) fecal batches before (t0) and after simulated (in vitro) colonic fermentation $\left(\mathrm{t} 24 ; 24 \mathrm{~h}\right.$ at $37^{\circ} \mathrm{C}$ ) with and without the innovative synbiotic NatuREN G (NG). Fecal batches with healthy subjects (HC) feces were used as the control. The concentration of NMR compounds is summarized as the average of two independent analyses \pm SD. The concentration of FAAs is singularly reported (average expressed as a middle bar). * Significantly different compounds' concentrations (multiple t-test using the Sidak-Bonferroni correction, $p<0.05)$ compared with the relative baseline $(\mathrm{t} 0)$.

\section{Discussion}

To develop an innovative synbiotic with the prospective purpose of being used in nephropathy, we evaluated different probiotics, antioxidants, and prebiotics. Starting from the evidence that CKD patients show an increased incidence of oxidative stress [35] and that, in nephropathy, oxidative unbalance is due to increased production of reactive oxygen species [36], we characterized different antioxidants for the development of an innovative synbiotic. The applied selection methods are primarily based on the evaluation of probiotics' ability to grow in the presence of antioxidants and prebiotics. Some antioxidants have antimicrobial activities [37-39] and, for this reason, the first analyses were carried out on probiotics in the presence of antioxidants. Twenty-five probiotics, previously isolated from animal and human feces or commercially available formulations, were used. The tested bacteria belonged to the two main groups of probiotics, Bifidobacteria and lactobacilli. In the two last decades, evidence widely highlighted the beneficial roles of these two taxa on host 
health [40-42]. Both of these probiotics are recognized as the main saccharolytic bacteria of a healthy human gut [43]. We specifically focused on them also because of the critical lack of Bifidobacterium and lactobacilli frequently found in CKD [8]. We selected those probiotics that, in the presence of antioxidants, showed the highest degree of acidification. Then, the same criterion was adopted for prebiotics evaluation, with the aim of selecting high SCFA-producing bacteria. In healthy conditions, SCFAs are the main energy source for intestinal epithelial cells; additionally, they are primarily involved in maintaining intestinal $\mathrm{pH}$ within optimal ranges [18].

Subsequently, we evaluated the in vitro effect(s) of the resulting combination of antioxidants and prebiotics. Experimental treatments were initially tested in fecal media prepared from feces collected from healthy subjects. Subsequently, the same was also performed with fecal media prepared from feces collected from CKD patients at stage IIIb-IV, i.e., the worst condition before the ESRD stage when dialysis becomes essential. In the evaluation of the obtained results, we underline the widely recognized limitations that are innate in our experimental conditions due to the impact of sampling fecal microbiota communities [44]. However, many (12 out of 25) of the evaluated probiotics showed promising results, at least in our in vitro analyses. Therefore, the total free amino acids (FAAs) analysis was an intermediate step, playing a pivotal role in decreasing the mainly proteolytic metabolism typical of nephropathy [45]. In CKD, the dysbiotic, highly proteolytic, microbial patterns determine the increase in uremic toxins, e.g., IS and pCS, produced from urea and other nitrogenous compounds [8]. Moreover, due to low kidney functionality, CKD patients are unable to excrete waste metabolites (including urea, ammonia, and uremic toxins), which, in turn, contribute to $\mathrm{pH}$ increase in the intestinal environment [7]. Additionally, urea and ammonia are primarily involved in the tight junctions' disruption in CKD [46]. Based on these considerations, the FAAs analysis allowed us to reduce the number of selected probiotics from 12 to 4 strains. In fecal media obtained using CKD feces, only B. animalis BLC1, L. delbrueckii SP5, Lc. casei LC4P1, and Lp. plantarum LPAL showed lower proteolytic activity. This result confirmed the evidence of the high protease/peptidase activity of lactic acid bacteria. The proteolytic activity of lactic acid bacteria plays a role in cheese ripening [47] and, through hydrolysis of gliadins and related epitopes, in ameliorating the symptomatology related to gluten malabsorption and celiac disease [48,49].

Therefore, the last step in the adopted workflow was the characterization of the ability of the four selected probiotics to produce SCFA, given the evidence discussed above $[17,20,21]$. The largest spectrum of SCFAs was achieved using B. animalis BLC1 and Lc. casei LC4P1. Thus, a first innovative synbiotic was developed (NatuREN P), which comprised B. animalis $\mathrm{BLC1}$, Lc. casei LC4P1, FOS, inulin, and pomegranate seed extract. The stability tests showed that, unfortunately, a critical decrease in the probiotics' viability occurred after two months of storage. For this reason, based on the promising results obtained upon administration of polyphenols-enriched tomato and red grape skin extracts in colitis mouse models $[27,34]$, we then evaluated a polyphenolic mixture, named Polimix, including quercetin, resveratrol, and proanthocyanidins. Polimix simulates the polyphenol profile classes of transgenic tomato varieties and red grape skin. Thus, a second innovative synbiotic was developed and named NatuREN G, which comprised B. animalis BLC1, Lc. casei LC4P1, FOS, inulin, quercetin, resveratrol, proanthocyanidins from grapeseed (Vitis vinifera L.) powder extract, maltodextrins from corn, and sodium cyclamate. The stability tests performed on NatuREN G showed that the probiotic cell density remained approximatively stable for two months of product storage, at both room and refrigerated temperatures. Additionally, only a slight decrease in cell density was found after six months of storage.

Hence, the development of the present synbiotic occurred within an ongoing research project in which different treatments were being administered to CKD patients. The common aim of previous works was to evaluate whether different dietary interventions with probiotics and prebiotics might ameliorate pathognomonic features in nephropathy. The literature in this field reports conflicting results, where not all treatments reached the 
expected outcomes. In line with this, Takayama et al. found that the administration of Bifidobacterium longum was effective in decreasing indoxyl sulfate (IS) in hemodialyzed patients [22]. The collected data showed that five weeks of treatment were sufficient to decrease serum levels of IS. Similarly, a mixture of different probiotics, including Streptococcus, Lactobacillus, and Bifidobacterium strains, was administered to hemodialyzed patients [23], even if, in this work, no changes in TMAO levels were found in plasma. Concerning prebiotics, four weeks of treatment with resistant starch showed significant decreases in both the IS and IL-6 plasma levels of hemodialyzed patients [50], while oligofructose-enriched inulin showed its impact by decreasing $p$ CS levels [51]. Other trials focused on the effects of FOS administration to CKD patients. In one of these studies, FOS produced a reduction in circulating $p C S$, even if no changes in IS levels were recorded [52]. Conversely, another study using FOS reported an amelioration in inflammatory parameters and endothelial integrity, whereas only slight but not significant differences in $p C S$ were found [53].

Before industrial scale-up, NatuREN G was tested in fecal batches prepared from $\mathrm{HC}$ and CKD subjects, showing promising results, although confirmation in vivo remains necessary. In detail, a significant increase in both lactic acid bacteria and lactobacilli was found in CKD fecal batches. In addition, in both batches (from HC and CKD) an increase in bifidobacterial species was found after $24 \mathrm{~h}$ of the addition of NatuREN G. As these results only partially reproduce the nephropathic intestinal environment, it seems that NatuREN $\mathrm{G}$ may be able to modify the microbial balance toward a eubiotic microbiota composition. Notably, the VOCs analysis showed that the innovative synbiotic NatuREN G produced an increase in SCFAs (acetic and propanoic acids) in CKD samples, $24 \mathrm{~h}$ after its addition. Additionally, a clear reduction in the uremic toxin concentration was found through NRM analysis and confirmed by amino acids detection. This result suggests that the innovative synbiotic NatuREN G seems to be able to reduce the metabolic pathways leading to uremic toxin precursors, at least in in vitro analyses.

We are conscious that the observed findings need to be confirmed with an in vivo application due to the limitations that markedly characterize in vitro approaches. However, previous trials reported promising outcomes of treatments with synbiotics [24-26], possibly due to the synergistic interaction between probiotics and prebiotics. Treatment based on the administration of lactobacilli and bifidobacterial strains together with galactooligosaccharides (GOS) decreased $p$ CS levels [24]. A similar outcome was obtained in CKD patients (stage IIIb-IV), administering a mixture of Bifidobacteria and lactic acid bacteria (lactobacilli and streptococci) with prebiotics (FOS, inulin, and resistant starch) for four weeks [25]. The same was also found in another set of CKD patients, in which a similar synbiotic containing a probiotic consortium (Bifidobacteria, lactobacilli, and streptococci) and prebiotics (inulin, FOS, and GOS) produced a reduction in $p$ CS [26].

In our opinion, the approach adopted to constitute this innovative synbiotic, following a step-by-step workflow before proceeding with in vivo evaluation, can be considered among the strengths of this study. The probiotics were selected after evaluating their interaction with other constituents and, subsequently, were selected for their biological activities. Moreover, the in vitro evaluation of fecal microbiota allowed us to obtain preliminary evidence about their effects when in the presence of viable microbiota. Nonetheless, some limitations need to be acknowledged. Firstly, although feces were collected in sterile stool containers filled to over four-fifths with the aim of reducing the headspace and processed within $6 \mathrm{~h}$ from the collection, the used fecal microbiota could have been different from real intestinal microbiota. Additionally, the in vitro analyses were unable to reproduce all variables characterizing the host and, therefore, the in vivo evaluation of NatuREN G remains essential.

\section{Conclusions}

This study provides evidence that the innovative synbiotic NatuREN G may be able to decrease the level of uremic toxins, at least under in vitro conditions simulating dysbiosis and some of the pathognomonic characteristics linked to nephropathy. The innovative 
synbiotic produced some shifts in the main microbial groups, favoring saccharolytic ones and suppressing the overgrowth of proteolytic bacteria. This shift might be able to increase the metabolism of SCFA, also leading to restored intestinal $\mathrm{pH}$ values, reducing the epithelial layer disruption, and, therefore, delaying ESRD onset and the need for dialysis. However, due to a critical lack of systems reproducing real host physiology, particularly given the biases related to short-term air exposure of collected feces, possibly affecting the composition of fecal microbiota, in vivo evaluation of NatuREN G is essential.

Supplementary Materials: The following are available online at https:/ /www.mdpi.com/article/10 $.3390 /$ microorganisms9061316/s1. Table S1: Main polyphenol classes detected in wild type (WT) tomato (cv. Moneymaker) and the high polyphenol enriched transgenic lines Indigo, ResTom, and Bronze. Table S2: Analysis of pomegranate juice extracted from different varieties, specifically Kamel, Emek, Ako, and Wonderful one. Table S3: Comparison between the high-polyphenol-enriched Bronze line and grape (white and red) skin in terms of the main classes of polyphenols. Table S4: Main findings leading to the constitution of NatuREN G. Figure S1: (A) Change in $\mathrm{pH}(\Delta \mathrm{pH})$ after $24 \mathrm{~h}$ of probiotics growth at $37^{\circ} \mathrm{C}$ in artisanal MRS ((artMRS), $2 \mathrm{~g} / \mathrm{L}$ of glucose) with the addition of a polyphenolic mixture (5 g/L; quercetin, resveratrol, and proanthocyanidins; ratio 64:23:13, respectively). (B) Probiotic cell density $(\log \mathrm{CFU} / \mathrm{mL})$ after $24 \mathrm{~h}$ of growth in artMRS $(2 \mathrm{~g} / \mathrm{L}$ of glucose) used alone or supplemented with the polyphenolic mixture $(5 \mathrm{~g} / \mathrm{L}$; quercetin, resveratrol, and proanthocyanidins; ratio 64:23:13, respectively).

Author Contributions: Conceptualization, M.V., F.M.l.F., L.G. and M.D.A.; methodology, M.S.L., A.S. (Angelo Santino), L.G. and M.D.A.; software, M.V.; validation, M.S.L., A.S. (Angelo Santino), G.D. and M.D.A.; formal analysis, M.V., G.C. and A.S. (Aurelia Scarano); investigation, M.V., G.C., M.S.L. and A.S. (Angelo Santino); resources, S.F., L.G. and M.D.A.; data curation, M.V. and M.D.A.; writing—original draft preparation, M.V.; writing—review and editing, M.V., G.C., F.M., A.S. (Angelo Santino) and M.D.A.; visualization, F.M. and M.D.A.; supervision, M.D.A.; project administration, S.F., L.G. and M.D.A.; funding acquisition, F.M.1.F., S.F., G.D., L.G. and M.D.A. All authors have read and agreed to the published version of the manuscript.

Funding: This study was funded by the XUANRO4-NATURE-Nuovo Approccio per la riduzione delle Tossine Uremiche REnali, REGIONE PUGLIA-FSC 2007-2013 Ricerca. Intervento “Cluster Tecnologici Regionali".

Institutional Review Board Statement: The study was conducted according to the guidelines of the Declaration of Helsinki and approved by the Ethical Committee of the Azienda OspedalieroUniversitaria Consorziale Policlinico of Bari, Italy (Authorization nr. 0673/2017, 16 May 2017).

Informed Consent Statement: Informed consent was obtained from all subjects involved in the study.

Data Availability Statement: The data presented in this study are available on request from the corresponding author.

Acknowledgments: We thank all the partnerships of the NATURE project. We thank Sonya Siragusa for technical assistance with the laboratory experiments.

Conflicts of Interest: S.F. is the Chief Executive Officer of Research Center «Dr. Sergio Fontana 1900-1982» of Farmalabor. F.M.l.F. is the research and development manager of Research Center «Dr. Sergio Fontana 1900-1982» of Farmalabor. The other authors declare no conflicts of interest.

\section{Appendix A}

\section{Appendix A.1. Pomegranate Juice Extraction}

All pomegranate fruits were collected during the 2015-2016 commercial harvest from Cairo \& Doutcher farm in Copertino (Lecce, Italy). Freshly harvested fruits of the same size, without any physical defects, were randomly selected, washed with tap water, dried, cut in half, and squeezed by a professional electric juicer (Fimar, Villa Verucchio (Rimini), Italy). The juice was immediately stored at $-80{ }^{\circ} \mathrm{C}$ until analysis. Four independent extractions (biological replicas) were performed using ten fruits each. All analyses were performed in triplicate (sampling replicas) for each extract. 


\section{Appendix A.2. Determination of Moisture, Ash, Total Soluble Solids, and $p H$}

Moisture was determined gravimetrically after drying $1.0 \mathrm{~g}$ aliquots of the pomegranate extract at $105^{\circ} \mathrm{C}$ in a Büchi TO-50 infrared dryer (BÜCHI Labortechnik AG, Flawil, Switzerland). Total soluble solids were measured using a digital refractometer (DBR95 Giorgio Bormac S.r.l., Carpi (Modena), Italy) and the results are expressed as ${ }^{\circ}$ Brix. Ash content was determined on $5.0 \mathrm{~g}$ aliquots of each sample using a muffle furnace at $525^{\circ} \mathrm{C}$ for $6 \mathrm{~h}$, according to the AOAC (2005) method [54]. The ash content is expressed as g per $100 \mathrm{~g}$ of fresh weight $(\mathrm{g} / 100 \mathrm{~g}$ f.w.). The $\mathrm{pH}$ of the extract was determined at room temperature using a $\mathrm{pH}$ meter (Mettler Toledo, Columbus, $\mathrm{OH}, \mathrm{USA}$ ).

\section{Appendix A.3. Total Carbohydrates, Total Polysaccharides, Pectins, and Starch Determination}

Total carbohydrates were determined with the phenol-sulfuric acid method using a Beckman DU 650 spectrophotometer (Beckman Coulter Inc., Brea, CA, USA) according to Nielsen [55]. Total polysaccharide content was measured with the same method on precipitates obtained by mixing $5 \mathrm{~mL}$ juice aliquots with ethanol ( $70 \%$ final concentration) and centrifuging at $6000 \times g$ for $10 \mathrm{~min}$. Pectins were quantified using the spectrophotometric method proposed by Blumenkrantz and Asboe-Hansen [56]. Total starch was determined using the Megazyme Total Starch Assay Kit (Megazyme International Ireland, Bray, Ireland), based on the AOAC official methods 996.11 [57].

\section{Appendix A.4. Analysis of Soluble Sugars and Organic Acids}

Soluble sugars and organic acids in the extracts were analyzed using high-performance liquid chromatography (HPLC), as described by Castellari et al. [58]. Identification and quantification of sugars and organic acids were performed by comparison of peak retention times and areas with those of external standards.

\section{Appendix A.5. Ascorbic Acid (AsA) and Dehydroascorbic Acid (DHA) Determination}

AsA and DHA were extracted using 6\% metaphosphoric acid. Their concentrations were determined on triplicate aliquots of the extract $(0.1 \mathrm{~g})$ using a Beckman DU 650 spectrophotometer, set at a wavelength of $525 \mathrm{~nm}$ [59].

\section{Appendix A.6. Extraction and Determination of Soluble and Insoluble-Bound Phenolics}

Phenols were extracted according to Adom et al. [60]. Briefly, $0.05 \mathrm{~g}$ of extracted juice was mixed with $1 \mathrm{~mL}$ of $80 \%(v / v)$ ethanol and extracted at room temperature for $10 \mathrm{~min}$ under constant shaking (300 rpm). After centrifugation $(2500 \times \mathrm{g}$ for $10 \mathrm{~min})$, the supernatant containing the soluble phenolic compounds was recovered. The extraction was repeated twice, and the supernatants were combined.

The insoluble-bound phenols were extracted from the pellets resulting from the soluble phenols extraction. The pellets were sequentially washed twice with $100 \%$ methanol and a mixture of chloroform/methanol/water $(1: 1: 1, v / v)$ and once with $100 \%$ acetone. After each washing step, the extracts were centrifuged $(8800 \times \mathrm{g}$ for $7 \mathrm{~min})$ and the supernatants discarded. The residues were treated with $1.0 \mathrm{M} \mathrm{NaOH}(1 \mathrm{~mL})$ at room temperature for $1 \mathrm{~h}$ under shaking and a nitrogen atmosphere. The mixtures were acidified to $\mathrm{pH} 2(12 \mathrm{M} \mathrm{HCl})$ and extracted three times with $500 \mu \mathrm{L}$ of $100 \%$ ethyl acetate. The ethyl acetate fraction was evaporated to dryness. Phenolic compounds in dried extract were dissolved in $500 \mu \mathrm{L}$ of $80 \%$ ethanol $(v / v)$.

Phenolic content was determined on each extract (soluble and insoluble-bound phenolics) according to the method of Xu et al. [61]. Briefly, $50 \mu \mathrm{L}$ of extract was mixed with $50 \mu \mathrm{L}$ of Folin-Ciocalteu's phenol reagent and $450 \mu \mathrm{L}$ distilled water. The mixture was kept at room temperature for $5 \mathrm{~min}$, and then $500 \mu \mathrm{L}$ of sodium carbonate $(7 \% \times)$ was added. After brining the mixture to final volume $(1250 \mu \mathrm{L})$ with distilled water, the mixture was left at room temperature in the dark for $90 \mathrm{~min}$. The absorbance was read at $750 \mathrm{~nm}$ in a Beckman DU650 spectrophotometer. The amounts of total phenols were calculated using 
gallic acid (GA) as the calibration standard within the range of 0-12 $\mu \mathrm{g}$ GA/100 $\mu \mathrm{L}$. The results are expressed as $\mathrm{mg}$ GA equivalents (GAE)/g fresh weight (f.w.).

\section{Appendix A.7. Extraction and Determination of Flavonoids and Proanthocyanidins}

We mixed $0.3 \mathrm{~g}$ of each juice with $1.5 \mathrm{~mL}$ of $100 \%$ methanol $(v / v)$. The mixture was then shaken at $4{ }^{\circ} \mathrm{C}$ for $16 \mathrm{~h}$, then centrifuged at $8800 \times g$ for $10 \mathrm{~min}$. All supernatants were recovered and used for determining total flavonoid and proanthocyanidin contents.

The total flavonoid content was determined as described by Zhishen et al. [62]. We diluted $50 \mu \mathrm{L}$ of extract with distilled water to a final volume of $500 \mu \mathrm{L}$, and $30 \mu \mathrm{L}$ of $5 \% \mathrm{NaNO}_{2}$ was added. After $5 \mathrm{~min}, 60 \mu \mathrm{L}$ of $10 \% \mathrm{AlCl}_{3}$ was added, followed after a further 6 min with the addition of $200 \mu \mathrm{L}$ of $1 \mathrm{M} \mathrm{NaOH}$ and $210 \mu \mathrm{L}$ of distilled water. The absorbance was read at $510 \mathrm{~nm}$ in a Beckman DU650 spectrophotometer. The linear calibration curve was constructed using catechin $(0-400 \mu \mathrm{g} / \mathrm{mL})$. The results are expressed as $\mathrm{mg}$ of catechin equivalents (CE)/g f.w. Condensed tannins were determined according to Broadhurst and Jones [63]. We mixed $100 \mu \mathrm{L}$ of extract, contained in a test tube covered with aluminum foil, with $600 \mu \mathrm{L}$ of $4 \%$ vanillin-methanol solution and then with $300 \mu \mathrm{L}$ of $12 \mathrm{M}$ hydrochloric acid. The mixture was allowed to stand for $15 \mathrm{~min}$ at $20^{\circ} \mathrm{C}$ in the dark. The absorbance of the mixture was read at $500 \mathrm{~nm}$ in a Beckman DU650 spectrophotometer. The results are expressed as $\mathrm{mg}$ of catechin equivalents (CE)/g f.w., calculated based on a calibration curve (from 3.9 to $250 \mu \mathrm{g}$ catechin $/ \mathrm{mL}$ ).

\section{Appendix A.8. Extraction and Determination of Total Anthocyanins}

Total anthocyanins were extracted according to Zhao et al. [64]. Briefly, $0.5 \mathrm{~g}$ of each juice was mixed with $15 \mathrm{~mL}$ of methanol containing $0.1 \% \mathrm{HCl}$. The samples were stirred at room temperature and in the dark for $30 \mathrm{~min}$. Subsequently, they were centrifuged at $3900 \times \mathrm{g}$ for $30 \mathrm{~min}$ at $4{ }^{\circ} \mathrm{C}$ in a Beckman AllegraTM X-22 centrifuge. Supernatants were dried by evaporation at a constant temperature of $35^{\circ} \mathrm{C}$. The dried residue was suspended in $1 \mathrm{~mL}$ of distilled water.

The total anthocyanins (TA) were estimated using the $\mathrm{pH}$ differential method with two buffer systems: potassium chloride $(25 \mathrm{mM})$ buffer $\mathrm{pH} 1.0$ and sodium acetate $(0.4 \mathrm{M})$ buffer $\mathrm{pH} 4.5$ [65]. Briefly, $0.1 \mathrm{~mL}$ aliquots of each fraction were mixed with $0.9 \mathrm{~mL}$ corresponding buffers. The samples were left at room temperature and in the dark for $15 \mathrm{~min}$ and their absorbance values at 510 and $700 \mathrm{~nm}$ was determined (reading against water). The absorbance values were calculated as follows:

$\mathrm{A}=(\mathrm{A} 510 \mathrm{~nm}-\mathrm{A} 700 \mathrm{~nm}) \mathrm{pH} 1.0-(\mathrm{A} 510 \mathrm{~nm}-\mathrm{A} 700 \mathrm{~nm}) \mathrm{pH} 4.5$

For the determination of total anthocyanins content, the following formula was used:

$$
\mathrm{TA}(\mathrm{mg} / \mathrm{L})=[\mathrm{A} \times \mathrm{MW} \times \mathrm{DF} \times 1000] \times 1 / \mathrm{MA}
$$

where A is absorbance, MW is the molecular weight of cyanidin-3-glucoside $(449.2 \mathrm{~g} / \mathrm{mol})$, $\mathrm{DF}$ is the dilution factor, and MA is the molar absorptivity coefficient of cyanidin-3glucoside $(26,900)$.

The final results are expressed as $\mu \mathrm{g}$ of cyanidin-3-glucoside/g f.w.

\section{Appendix A.9. Antioxidant Activity Determination}

Molecules with antioxidants activity were extracted according to Hdider et al. [66], with slight modifications. Briefly, $0.4 \mathrm{~g}$ of each juice was sequentially extracted with $100 \%$ methanol and $100 \%$ acetone (liposoluble antioxidants) under constant shaking (300 rpm) at room temperature in the dark for $1 \mathrm{~h}$. Samples were centrifuged at $2500 \times \mathrm{g}$ for $10 \mathrm{~min}$. Supernatants were recovered and used for the antioxidant activity assay. Hydrophilic antioxidant activity (HAA) and lipophilic antioxidant activity (LAA) were measured by the Trolox equivalent antioxidant capacity (TEAC) assay as described by Re et al. [67], using the ABTS discoloration method. The absorbance decrease was measured at $734 \mathrm{~nm}$ in a Beckman DU650 spectrophotometer. The linear calibration curves ranged from 0 to $15 \mu \mathrm{M}$ 
Trolox. The antioxidant activity of the samples was calculated based on the inhibition exerted by standard Trolox concentrations at $734 \mathrm{~nm}$, with inhibition time fixed at $10 \mathrm{~min}$. Total antioxidant activity (TAA) was calculated as the sum of HAA and LAA. Results are expressed as $\mu \mathrm{mol}$ of Trolox equivalents (TE)/g f.w.

\section{References}

1. Levey, A.S.; Eckardt, K.U.; Tsukamoto, Y.; Levin, A.; Coresh, J.; Rossert, J.; Zeeuw, D.D.E.; Hostetter, T.H.; Lameire, N.; Eknoyan, G. Definition and classification of chronic kidney disease: A position statement from Kidney Disease: Improving Global Outcomes (KDIGO). Kidney Int. 2005, 67, 2089-2100. [CrossRef] [PubMed]

2. Hsu, C.Y.; Iribarren, C.; McCulloch, C.E.; Darbinian, J.; Go, A.S. Risk factors for end-stage renal disease: 25-year follow-up. Arch. Intern. Med. 2009, 169, 342-350. [CrossRef] [PubMed]

3. Stubbs, J.R.; House, J.A.; Ocque, A.J.; Zhang, S.; Johnson, C.; Kimber, C.; Schmidt, K.; Gupta, A.; Wetmore, J.B.; Nolin, T.D.; et al. Serum trimethylamine-N-oxide is elevated in CKD and correlates with coronary atherosclerosis burden. J. Am. Soc. Nephrol. 2016, 27, 305-313. [CrossRef] [PubMed]

4. Anders, H.J.; Andersen, K.; Stecher, B. The intestinal microbiota, a leaky gut, and abnormal immunity in kidney disease. Kidney Int. 2013, 83, 1010-1016. [CrossRef]

5. Mikusic, N.L.R.; Kouyoumdzian, N.M.; Choi, M.R. Gut microbiota and chronic kidney disease: Evidence and mechanisms that mediate a new communication in the gastrointestinal-renal axis. Pflügers Arch. Eur. J. Physiol. 2020, 472, 303-320. [CrossRef]

6. Claro, L.M.; Moreno-Amaral, A.N.; Gadotti, A.C.; Dolenga, C.J.; Nakao, L.S.; Azevedo, M.L.; De Noronha, L.; Olandoski, M.; De Moraes, T.P.; Stinghen, A.E.M.; et al. The impact of uremic toxicity induced inflammatory response on the cardiovascular burden in chronic kidney disease. Toxins 2018, 10, 384. [CrossRef]

7. Wu, P.; Lin, T.; Ho, H.J.; Tseng, C.; Lin, Y.; Liang, S.; Lee, H.; Kuo, M.; Hung, S.; Chiu, Y.; et al. Differences in Gut Microbiota proles and Functions between End-Stage Renal Disease and Healthy Populations. Available online: https://www.researchsquare. com/article/rs-82652/v1 (accessed on 4 February 2021).

8. Gryp, T.; Huys, G.R.; Joossens, M.; Van Biesen, W.; Glorieux, G.; Vaneechoutte, M. Isolation and quantification of uremic toxin precursor-generating gut bacteria in chronic kidney disease patients. Int. J. Mol. Sci. 2020, 21, 1986. [CrossRef]

9. Evenepoel, P.; Poesen, R.; Meijers, B. The gut-kidney axis. Pediatr. Nephrol. 2017, 32, 2005-2014. [CrossRef]

10. Lehto, M.; Groop, P.H. The gut-kidney axis: Putative interconnections between gastrointestinal and renal disorders. Front. Endocrinol. 2018, 9, 553. [CrossRef]

11. Di Iorio, B.R.; Rocchetti, M.T.; De Angelis, M.; Cosola, C.; Marzocco, S.; Di Micco, L.; di Bari, I.; Accetturo, M.; Vacca, M.; Gobbetti, M.; et al. Nutritional therapy modulates intestinal microbiota and reduces serum levels of total and free indoxyl sulfate and p-cresyl sulfate in chronic kidney disease (Medika Study). J. Clin. Med. 2019, 8, 1424. [CrossRef]

12. Fernandez-Prado, R.; Esteras, R.; Perez-Gomez, M.V.; Gracia-Iguacel, C.; Gonzalez-Parra, E.; Sanz, A.B.; Ortiz, A.; Sanchez-Nino, M.D. Nutrients turned into toxins: Microbiota modulation of nutrient properties in chronic kidney disease. Nutrients 2017, 9, 489. [CrossRef]

13. Rocchetti, M.T.; Di Iorio, B.R.; Vacca, M.; Cosola, C.; Marzocco, S.; Bari, I.D.; Calabrese, F.M.; Ciarcia, R.; De Angelis, M.; Gesualdo, L. Ketoanalogs' effects on intestinal microbiota modulation and uremic toxins serum levels in chronic kidney disease (Medika2 Study). J. Clin. Med. 2021, 10, 840. [CrossRef] [PubMed]

14. Borges, N.A.; Carmo, F.L.; Stockler-Pinto, M.B.; de Brito, J.S.; Dolenga, C.J.; Ferreira, D.C.; Nakao, L.S.; Rosado, A.; Fouque, D.; Mafra, D. Probiotic supplementation in chronic kidney disease: A double-blind, randomized, placebo-controlled trial. J. Ren. Nutr. 2018, 28, 28-36. [CrossRef]

15. Natarajan, R.; Pechenyak, B.; Vyas, U.; Ranganathan, P.; Weinberg, A.; Liang, P.; Mallappallil, M.C.; Norin, A.J.; Friedman, E.A.; Saggi, S.J. Randomized controlled trial of strain-specific probiotic formulation (Renadyl) in dialysis patients. BioMed Res. Int. 2014, 2014, 568571. [CrossRef]

16. Dehghani, H.; Heidari, F.; Mozaffari-Khosravi, H.; Nouri-Majelan, N.; Dehghani, A. Synbiotic supplementations for azotemia in patients with chronic kidney disease: A randomized controlled trial. Iran. J. Kidney Dis. 2016, 10, 351-357. [CrossRef] [PubMed]

17. Cosola, C.; De Angelis, M.; Rocchetti, M.T.; Montemurno, E.; Maranzano, V.; Dalfino, G.; Manno, C.; Zito, A.; Gesualdo, M.; Ciccone, M.M.; et al. Beta-glucans supplementation associates with reduction in p-cresyl sulfate levels and improved endothelial vascular reactivity in healthy individuals. PLOS ONE 2017, 12, e0169635. [CrossRef] [PubMed]

18. Den Besten, G.; van Eunen, K.; Groen, A.K.; Venema, K.; Reijngoud, D.; Bakker, B.M. The role of short-chain fatty acids in the interplay between diet, gut microbiota, and host energy metabolism. J. Lipid. Res. 2013, 54, 2325-2340. [CrossRef] [PubMed]

19. Campos-Perez, W.; Martinez-Lopez, E. Effects of short chain fatty acids on metabolic and inflammatory processes in human health. BBA Mol. Cell Biol. Lipids 2021, 1866, 158900. [CrossRef]

20. Pluznick, J.L. Gut microbiota in renal physiology: Focus on short-chain fatty acids and their receptors. Kidney Int. 2016, 90, 1191-1198. [CrossRef] [PubMed]

21. Li, L.; Ma, L.; Fu, P. Gut microbiota-derived short-chain fatty acids and kidney diseases. Drug Des. Dev. Ther. 2017, $11,3531$. [CrossRef]

22. Takayama, F.; Taki, K.; Niwa, T. Bifidobacterium in gastro-resistant seamless capsule reduces serum levels of indoxyl sulfate in patients on hemodialysis. Am. J. Kidney Dis. 2003, 41 (Suppl. 1), S142-S145. [CrossRef] 
23. Borges, N.A.; Stenvinkel, P.; Bergman, P.; Qureshi, A.R.; Lindholm, B.; Moraes, C.; Stockler-Pinto, B.; Mafra, D. Effects of probiotic supplementation on trimethylamine-n-oxide plasma levels in hemodialysis patients: A pilot study. Probiotics Antimicrob. Proteins 2019, 11, 648-654. [CrossRef]

24. Nakabayashi, I.; Nakamura, M.; Kawakami, K.; Ohta, T.; Kato, I.; Uchida, K.; Yoshida, M. Effects of synbiotic treatment on serum level of p-cresol in haemodialysis patients: A preliminary study. Nephrol. Dial. Transpl. 2011, 26, 1094-1098. [CrossRef]

25. Guida, B.; Germanò, R.; Trio, R.; Russo, D.; Memoli, B.; Grumetto, L.; Barbati, F.; Cataldi, M. Effect of short-term synbiotic treatment on plasma p-cresol levels in patients with chronic renal failure: A randomized clinical trial. Nutr. Metab. Cardiovasc. Dis. 2014, 24, 1043-1049. [CrossRef]

26. Rossi, M.; Johnson, D.W.; Morrison, M.; Pascoe, E.M.; Coombes, J.S.; Forbes, J.M.; Szeto, C.C.; McWhinney, B.C.; Ungerer, J.P.J.; Campbell, K.L. Synbiotics easing renal failure by improving gut microbiology (SYNERGY): A randomized trial. Clin. J. Am. Soc. Nephrol. 2016, 11, 223-231. [CrossRef] [PubMed]

27. Scarano, A.; Butelli, E.; De Santis, S.; Cavalcanti, E.; Hill, L.; De Angelis, M.; Giovinazzo, G.; Chieppa, M.; Martin, C.; Santino, A. Combined dietary anthocyanins, flavonols, and stilbenoids alleviate inflammatory bowel disease symptoms in mice. Front. Nutr. 2018, 4, 75. [CrossRef]

28. Filannino, P.; De Angelis, M.; Di Cagno, R.; Gozzi, G.; Riciputi, Y.; Gobbetti, M. How Lactobacillus plantarum shapes its transcriptome in response to contrasting habitats. Env. Microbiol. 2018, 20, 3700-3716. [CrossRef] [PubMed]

29. De Angelis, M.; Montemurno, E.; Piccolo, M.; Vannini, L.; Lauriero, G.; Maranzano, V.; Gozzi, G.; Serrazanetti, D.; Dalfino, G.; Gobbetti, M.; et al. Microbiota and metabolome associated with immunoglobulin A nephropathy (IgAN). PLoS ONE 2014, 9 , e99006. [CrossRef]

30. Dixon, E.; Clubb, C.; Pittman, S.; Ammann, L.; Rasheed, Z.; Kazmi, N.; Keshavarzian, A.; Pat Gillevet, P.; Huzefa Rangwala, H.; Couch, R.D. Solid-phase microextraction and the human fecal VOC metabolome. PLoS ONE 2011, 6, e18471. [CrossRef] [PubMed]

31. De Angelis, M.; Piccolo, M.; Vannini, L.; Siragusa, S.; De Giacomo, A.; Serrazzanetti, D.I.; Cristofori, F.; Guerzoni, M.E.; Gobbetti, M.; Francavilla, R. Fecal microbiota and metabolome of children with autism and pervasive developmental disorder not otherwise specified. PLOS ONE 2013, 8, e76993. [CrossRef]

32. Cammarota, G.; Ianiro, G.; Tilg, H.; Rajilić-Stojanović, M.; Kump, P.; Satokari, R.; Sokol, H.; Arkkila, P.; Pintus, C.; Hart, A.; et al. European consensus conference on faecal microbiota transplantation in clinical practice. Gut 2017, 66, 569-580. [CrossRef]

33. Beaumont, M.; Portune, K.J.; Steuer, N.; Lan, A.; Cerrudo, V.; Audebert, M.; Dumont, F.; Mancano, G.; Khodorova, N.; Andriamihaja, M.; et al. Quantity and source of dietary protein influence metabolite production by gut microbiota and rectal mucosa gene expression: A randomized, parallel, double-blind trial in overweight humans. Am. J. Clin. Nutr. 2017, 106, 1005-1019. [CrossRef] [PubMed]

34. Liso, M.; De Santis, S.; Scarano, A.; Verna, G.; Dicarlo, M.; Galleggiante, V.; Campiglia, P.; Mastronardi, M.; Lippolis, A.; Vacca, M.; et al. A bronze-tomato enriched diet affects the intestinal microbiome under homeostatic and inflammatory conditions. Nutrients 2018, 10, 1862. [CrossRef] [PubMed]

35. Dounousi, E.; Papavasiliou, E.; Makedou, A.; Ioannou, K.; Katopodis, K.P.; Tselepis, A.; Siamopoulos, K.C.; Tsakiris, D. Oxidative stress is progressively enhanced with advancing stages of CKD. Am. J. Kidney Dis. 2006, 48, 752-760. [CrossRef]

36. Gosmanova, E.O.; Le, N.A. Cardiovascular complications in CKD patients: Role of oxidative stress. Cardiol. Res. Pract. 2011, 2011, 1-8. [CrossRef] [PubMed]

37. Ozdal, T.; Sela, D.A.; Xiao, J.; Boyacioglu, D.; Chen, F.; Capanoglu, E. The reciprocal interactions between polyphenols and gut microbiota and effects on bioaccessibility. Nutrients 2016, 8, 78. [CrossRef]

38. Yahia, Y.; Benabderrahim, M.A.; Tlili, N.; Bagues, M.; Nagaz, K. Bioactive compounds, antioxidant and antimicrobial activities of extracts from different plant parts of two Ziziphus Mill. species. PLoS ONE 2020, 15, e0232599. [CrossRef] [PubMed]

39. Li, J.; Huang, S.Y.; Deng, Q.; Li, G.; Su, G.; Liu, J.; Wang, H.M.D. Extraction and characterization of phenolic compounds with antioxidant and antimicrobial activities from pickled radish. Food Chem. Toxicol. 2020, 136, 111050. [CrossRef]

40. Zhang, Z.; Lv, J.; Pan, L.; Zhang, Y. Roles and applications of probiotic Lactobacillus strains. Appl. Microbiol. Biot. 2018, 102, 8135-8143. [CrossRef]

41. Aw, W.; Fukuda, S. Protective effects of bifidobacteria against enteropathogens. Microb. Biotechnol. 2019, 12, 1097-1100. [CrossRef] [PubMed]

42. Ruiz, L.; Delgado, S.; Ruas-Madiedo, P.; Sánchez, B.; Margolles, A. Bifidobacteria and their molecular communication with the immune system. Front. Microbiol. 2017, 8, 2345. [CrossRef]

43. Papizadeh, M.; Rohani, M.; Nahrevanian, H.; Javadi, A.; Pourshafie, M.R. Probiotic characters of Bifidobacterium and Lactobacillus are a result of the ongoing gene acquisition and genome minimization evolutionary trends. Microb. Pathog. 2017, 111, 118-131. [CrossRef] [PubMed]

44. Bellali, S.; Lagier, J.C.; Raoult, D.; Bou Khalil, J. Among live and dead bacteria, the optimization of sample collection and processing remains essential in recovering gut microbiota components. Front. Microbiol. 2019, 10, 1606. [CrossRef] [PubMed]

45. Montemurno, E.; Cosola, C.; Dalfino, G.; Daidone, G.; De Angelis, M.; Gobbetti, M.; Gesualdo, L. What would you like to eat, Mr CKD microbiota? A Mediterranean diet, please! Kidney Blood Press. Res. 2014, 39, 114-123. [CrossRef]

46. Lau, W.L.; Vaziri, N.D. The leaky gut and altered microbiome in chronic kidney disease. J. Ren. Nutr. 2017, 27, 458-461. [CrossRef] [PubMed] 
47. Ardö, Y.; Pettersson, H.E. Accelerated cheese ripening with heat treated cells of Lactobacillus helveticus and a commercial proteolytic enzyme. J. Dairy Res. 1988, 55, 239-245. [CrossRef]

48. Francavilla, R.; Cristofori, F.; Vacca, M.; Barone, M.; De Angelis, M. Advances in understanding the potential therapeutic applications of gut microbiota and probiotic mediated therapies in celiac disease. Expert Rev. Gastroent. 2020, 14, 323-333. [CrossRef] [PubMed]

49. De Angelis, M.; Siragusa, S.; Vacca, M.; Di Cagno, R.; Cristofori, F.; Schwarm, M.; Pelzer, S.; Flügel, M.; Speckmann, B.; Francavilla, R.; et al. Selection of gut-resistant bacteria and construction of microbial consortia for improving gluten digestion under simulated gastrointestinal conditions. Nutrients 2021, 13, 992. [CrossRef]

50. Esgalhado, M.; Kemp, J.A.; Azevedo, R.; Stockler-Pinto, M.B.; Dolenga, C.J.; Borges, N.A.; Nakao, L.S.; Mafra, D. Could resistant starch supplementation improve inflammatory and oxidative stress biomarkers and uremic toxins levels in hemodialysis patients? A pilot randomized controlled trial. Food Funct. 2018, 9, 6508-6516. [CrossRef]

51. Meijers, B.K.I.; De Preter, V.; Verbeke, K.; Vanrenterghem, Y.; Evenepoel, P. p-Cresyl sulfate serum concentrations in haemodialysis patients are reduced by the prebiotic oligofructose-enriched inulin. Nephrol. Dial. Transplant. 2010, 25, 219-224. [CrossRef]

52. Ramos, C.I.; Armani, R.G.; Canziani, M.E.F.; Dalboni, M.A.; Dolenga, C.J.R.; Nakao, L.S.; Campbell, K.L.; Cuppari, L. Effect of prebiotic (fructooligosaccharide) on uremic toxins of chronic kidney disease patients: A randomized controlled trial. Nephrol. Dial. Transplant. 2019, 34, 1876-1884. [CrossRef]

53. Armani, R.G.; Carvalho, A.B.; Ramos, C.I.; Hong, V.; Bortolotto, L.A.; Cassiolato, J.L.; Oliveira, N.F.; Cieslarova, Z.; do Lago, C.L.; Klassen, A.; et al. Effect of fructooligosaccharide on endothelial function in CKD patients: A randomized controlled trial. Nephrol. Dial. Transplant. 2021, 7, gfaa335. [CrossRef] [PubMed]

54. Association of Official Analytical Chemists. Official Methods of Analysis of AOAC International, 18th ed.; Association of Official Analytical Chemists International: Gaithersburg, MD, USA, 2005.

55. Nielsen, S.S. Total carbohydrate by phenol-sulfuric acid method. In Food Analysis Laboratory Manual; Food Science Text Series; Springer: Cham, Switzerland, 2017; pp. 137-141. [CrossRef]

56. Blumenkrantz, N.; Asboe-Hansen, G. New method for quantitative determination of uronic acids. Anal. Biochem. 1973, 54, 484-489. [CrossRef]

57. McCleary, B.V.; Gibson, T.S.; Mugford, D.C. Measurement of total starch in cereal products by amyloglucosidase- $\alpha$-amylase method: Collaborative study. J. AOAC Int. 1997, 80, 571-579. [CrossRef]

58. Castellari, M.; Versari, A.; Spinabelli, U.; Galassi, S.; Amati, A. An improved HPLC method for the analysis of organic acids, carbohydrates and alcohols in grape musts and wines. J. Liq. Chromatogr. Relat. Technol. 2000, 23, 2047-2056. [CrossRef]

59. Kampfenkel, K.; Van Montagu, M.; Inzè, D. Extraction and determination of ascorbate and dehydroascorbate from plant tissue. Anal. Biochem. 1995, 225, 165-167. [CrossRef]

60. Adom, K.K.; Sorrells, M.E.; Liu, R.H. Phytochemical profiles and antioxidant activity of wheat varieties. J. Agric. Food Chem. 2003, 51, 7825-7834. [CrossRef]

61. Xu, G.; Liu, D.; Chen, J.; Ye, X.; Ma, Y.; Shi, J. Juice components and antioxidant capacity of citrus varieties cultivated in China. Food Chem. 2008, 106, 545-551. [CrossRef]

62. Zhishen, J.; Mengcheng, T.; Jianming, W. The determination of flavonoid contents in mulberry and their scavenging effects on superoxide radicals. Food Chem. 1999, 64, 555-559. [CrossRef]

63. Broadhurst, R.B.; Jones, W.T. Analysis of condensed tannins using acidified vanillin. J. Sci. Food Agric. 1978, $29,788-794$. [CrossRef]

64. Zhao, X.; Yuan, Z.; Fang, Y.; Yin, Y.; Feng, L. Characterization and evaluation of major anthocyanins in pomegranate (Punica granatum L.) peel of different cultivars and their development phases. Eur. Food Res. Technol. 2013, 236, 109-117. [CrossRef]

65. Ozgen, M.; Durgaç, C.; Serçe, S.; Kaya, C. Chemical and antioxidant properties of pomegranate cultivars grow in the Mediterranean region of Turkey. Food Chem. 2008, 111, 703-706. [CrossRef]

66. Hdider, C.; Ilahy, R.; Tlili, I.; Lenucci, M.S.; Dalessandro, G. Effect of the stage of maturity on the antioxidant content and antioxidant activity of high-pigment tomato cultivars grown in Italy. Food 2013, 7, 1-7.

67. Re, R.; Pellegrini, N.; Proteggente, A.; Pannala, A.; Yang, M.; Rice-Evans, C. Antioxidant activity applying and improved ABTS radical cation decolorization assay. Free Radic. Biol. Med. 1999, 26, 1231-1237. [CrossRef] 